\title{
The auxin transporter PIN1 and the cytokinin transporter AZG1 interact to regulate the root stress response
}

\author{
Tessi $\mathrm{TM}^{1 *}$, Shahriari $\mathrm{M}^{2 *}$, Maurino $\mathrm{VG}^{3 *}$, Meissner $\mathrm{E}^{4}$, Novak $\mathrm{O}^{5}$, Pasternak $\mathrm{T}^{2}$, Schumacher \\ $\mathrm{BS}^{6}$, Flubacher $\mathrm{NS}^{2}$, Nautscher $\mathrm{M}^{2}$, Williams $\mathrm{A}^{2}$, Kazimierczak $Z^{2}$, Strnad $\mathrm{M}^{5}$, Thumfart JO${ }^{7 \|}$, \\ Palme $\mathrm{K}^{2,8,9}$, Desimone $\mathrm{M}^{1+}$ and Teale $\mathrm{WD}^{2+}$
}

\section{Affiliations}

1. Instituto Multidisciplinario de Biología Vegetal, Velez Sarsfield 249, 5000 Córdoba, Argentina.

2. Institute of Biology II, University of Freiburg, Schänzlestrasse 1, 79104 Freiburg, Germany.

3. Department of Molecular Plant Physiology, Institute of Molecular Physiology and Biotechnology of Plants, University of Bonn, Kirschalle 1, 53115 Bonn, Germany.

4. Division of Naturschutz, Department Biology, Philipps-Universität Marburg, Karl-vonFrisch-Straße 8, 35032 Marburg

5. Laboratory of Growth Regulators, Institute of Experimental Botany ASCR and Palacky

6. Zentrum für Molekularbiologie der Pflanzen, Universität Tübingen, Auf der

Morgenstelle 1, 72076 Tübingen, Germany.

7. Institute of Physiology II, Faculty of Medicine, University of Freiburg, Hermann-HerderStrasse 7, 79104 Freiburg, Germany.

8. Centre of Biological Systems Analysis, University of Freiburg, 79104 Freiburg, Germany.

9. BIOSS Centre for Biological Signalling Studies, University of Freiburg, 79104 Freiburg, Germany.

* These authors contributed equally to this work

† Correspondence to: marchelodesimone@gmail.com; william.teale@biologie.unifreiburg.de

" Current address: Labormedizinisches Zentrum Ostschweiz, Lagerstrasse 30, 9470 Buchs SG, Switzerland. 


\begin{abstract}
Root system development is crucial for optimal growth and yield in plants, especially in suboptimal soil conditions. The architecture of a root system is environmentally responsive, enabling the plant to exploit regions of high nutrient density whilst simultaneously minimizing abiotic stress. Despite the vital contribution of root systems to the growth of both model and crop species, we know little of the mechanisms which regulate their architecture. One factor which is relatively well understood is the transport of auxin, a plant growth regulator which defines the frequency of lateral root (LR) initiation and the rate of LR outgrowth. Here we describe a search for proteins which regulate RSA by interacting directly with a key auxin transporter, PIN1. The native separation of PIN1 identified several co-purifying proteins. Among them, AZG1 was subsequently confirmed as a PIN1 interactor. AZG1-GFP fusions colocalized with PIN1 in procambium cells of the root meristem. Roots of azg1 plants contained less PIN1 and blocking proteolysis restored PIN1 levels, observations which are consistent with PIN1 being stabilized by AZG1 in the plasma membrane. Furthermore, we show that AZG1 is a cytokinin import protein; accordingly, azg1 plants are insensitive to exogenously applied cytokinin. In wild-type plants, the frequency of LRs falls with increasing salt concentration, a response which is not observed in azg1 $x$ azg2 plants, although their drought response is unimpaired. This report therefore identifies a potential point for auxin:cytokinin crosstalk in the environmentally-responsive determination of root system architecture.
\end{abstract}

\title{
Introduction
}

Soil salinity limits crop yields in many agricultural systems (Rozema and Flowers, 2008). In shaping root system architecture (RSA), salinity defines the surface area of the plant which is able to take nutrients and water from the soil. RSA is determined by complex signalling networks, guiding main and lateral roots to develop in response to $\mathrm{NaCl}$ concentration (Zolla et al., 2010; Julkowska and Testerink, 2017).

Factors which determine RSA, such as branching and growth rates are controlled by signals which are mediated by plant hormones. For example, artificially induced concentration maxima of the plant hormone auxin in root pericycle cells are necessary and sufficient to specify LR founder cells (Dubrovsky et al., 2008). Similar auxin maxima are generated naturally in protoxylem pole cells through an interaction between developmentally-defined auxin signaling oscillations in the root apical meristem (RAM) and the action of auxin transport proteins (Xuan et al., 2020). Throughout LR development, the generation and maintenance of dynamic auxin concentration maxima over several cell types is required for the correct initiation and development of a LR primordium (Benkova et al., 2003). The activity of several auxin transporters (particularly those of the PIN family) is necessary for these specific patterns of auxin distribution (Blilou et al., 2005; Benkova et al., 2003). A polar localization of PIN proteins in the plasma membrane directs the flux of auxin to define the site of auxin concentration maxima (Grieneisen et al, 2007; Petrasek et al, 2006). Furthermore, the distribution of several PIN proteins among polar plasma membrane domains is environmentally sensitive, acting to mediate RSA in response to gravity and mechanical obstacles in the soil (Ditengou et al., 2008; Friml et al., 2002; Ottenschläger et al., 2003). This 
sensitivity suggests a mechanism through which environmental factors may influence the rate at which roots grow and the extent to which they branch.

Auxin is counteracted by cytokinin during root development, with the ratio of the two hormones being a particularly important factor in the shaping of RSA (Aloni et al., 2006; dello Ioio et al., 2008; Muller \& Sheen, 2008). Cytokinins repress LR initiation through the action of CRE1/AHK4, an endoplasmic reticulum-localized receptor (Caesar et al, 2011; Laplaze et al, 2007). The cross-talk between auxin and cytokinin signaling cascades is complex, with the pathways having a reciprocal influence (Muller and Sheen, 2008; dello loio et al., 2008). PIN transcription is regulated by cytokinin to regulate root development (Bishopp et al, 2011a). However, in addition to exerting transcriptional control over polar auxin transport, cytokinins also promote the degradation of PIN1 in regenerating root tissue (Marhavý et al., 2011), potentially regulating the polarity of PIN proteins in developing LRs (Marhavý et al., 2014). However, although PIN1 phosphorylation status determines sensitivity to cytokinin in this respect, the proteins which directly mediate cytokinin-mediated sub-cellular PIN1 localisation remain obscure (Marhavý et al., 2014). Indeed, over and above their links to cytokinin signaling, proteins which interact directly with PINs remain largely elusive.

The dedicated transport of cytokinin is presently largely characterized by the loading of transzeatin (tZ) into xylem cells in roots (Zhang et al., 2014; Ko et al., 2014), and the loading of $\mathrm{N}^{6}\left(\Delta^{2}\right.$-isopentyl)adenine into phloem cells in leaves (Bürkle et al., 2003). Such long distance transport is thought to carry environmental information, such as on nutrient status, through the body of the plant. Short distance cytokinin transport has also been shown to play a role in the coordination of internal developmental cues; PURINE PERMEASE 14 (PUP14) is active in the developing embryo, and may even be involved in the relay of cytokinin signaling responses (Zürcher et al., 2016).

The generation of spatially distinct auxin and CK signalling domains is a key feature of vascular patterning (De Rybel et al., 2014; Ohashi-Ito et al., 2014), with the xylem axis being a region of high auxin signaling activity, and cells of the flanking cambial domains containing relatively high CK signaling activity (Bishopp et al., 2011a). Auxin-CK therefore appear to interact to drive distinct domains of root development, but a key question remains how these domains are coordinated both in the main root axis (De Rybel et al., 2014; Ohashi-Ito et al., 2014) and the LR (Chang et al., 2015, Bielach et al., 2012).

In this study we identify Arabidopsis thaliana AZG1 as a novel cytokinin import protein which directly interacts with PIN1. Our results are consistent with the hypothesis that AZG1 acts to stabilize PIN1 in the plasma membrane, potentially acting to sharpen the spatially separated boundary between auxin in protoxylem cells and cytokinin signaling maxima in procambial cells of the RAM. Moreover, we found that AZG1 is necessary to regulate LR density in response to $\mathrm{NaCl}$, conferring sensitivity to salinity but not to drought. 


\section{Materials and methods}

\section{Preparation of Arabidopsis plasma membranes}

Dark-grown MM2d Arabidopsis thaliana cell cultures (Menges and Murray, 2002) were harvested and washed with an equal volume of cold $20 \mathrm{mM} \mathrm{KCl}, 5 \mathrm{mM}$ EDTA before being lysed at $2^{\circ} \mathrm{C}$ with an automatic cell pressure lysis machine at $0.3 \mathrm{KBar}$ (Constant Systems) in homogenization buffer (50 mM Tris adjusted to $\mathrm{pH} 8.0$ with MES, $500 \mathrm{mM}$ sucrose, 10\% glycerol, 20 mM EDTA, 50 mM NaF, 0.6\% PVP (Mw 30,000 - 40,000), 10 mM ascorbic acid) containing a protease inhibitor cocktail (Roche). All subsequent steps were conducted on ice. Homogenate was centrifuged at $10,000 \times \mathrm{g}$ at $4^{\circ} \mathrm{C}$ for 10 minutes and filtered through two layers of Miracloth (Calbiochem) before centrifugation at $40,000 \times \mathrm{g}$ for one hour at $4^{\circ} \mathrm{C}$. Pellets were resuspended in microsome buffer $(5 \mathrm{mM}$ phosphate phosphate buffer $\mathrm{pH} 7.8$, containing $330 \mathrm{mM}$ sucrose, $2 \mathrm{mM}$ DTT, $10 \mathrm{mM} \mathrm{NaF}$ ) using $1 \mathrm{ml}$ of buffer for every $20 \mathrm{~g}$ of cells lysed (fresh weight). Solubilized protein complexes were prepared by treating microsomes with $0.5 \%$ Triton X-114 under gentle rotation for one hour before centrifugation at $100,000 \mathrm{x}$ $\mathrm{g}$ for 30 minutes. Plasma membranes were prepared by two-phase partitioning (Dextan T500/PEG3350) according to Kjellbom and Larsson (1984).

\section{Fractionation of Arabidopsis membrane protein complexes by free-flow electrophoresis} Isoelectric focussing (IEF)-free-flow electrophoresis (FFE) was conducted according to the manufacturer's instructions (BD) in a chamber of $0.5 \mathrm{~mm}$ thickness. Laminar flow of buffer was buffer was verified with $0.1 \%$ SPADNS and the chamber was treated with $0.05 \%$ HPMC before IEF-FFE amphylites ( $\mathrm{pH} 3-9 ; \mathrm{BD}$ ) were applied to inlets 2-6 of the chamber at a flow rate of $60 \mathrm{ml}$ per hour. Protein complexes were kept soluble by the addition of $0.8 \% \mathrm{n}$-octyl-B-Dpyranoside to all amphylites. A potential difference of $600 \mathrm{~V}$ was applied across the chamber and the $\mathrm{pH}$ gradient was verified using $\mathrm{pH}$ indicator dye mixture (BD). For each experiment, $300 \mu$ of microsomal sample was introduced to the chamber with a peristaltic pump at a flow rate of $700 \mu \mathrm{l}$ per hour (between 1 and $2 \mathrm{mg}$ protein per hour). Separated protein complexes were collected in a 96-well plate and each well was precipitated by the addition of a $10 \%$ volume of saturated trichloroacetic acid $(a q)$ and a $1 \%$ volume of $2 \%$ sodium deoxycholate before incubation on ice for one hour and centrifugation at 20,000 x g for $30 \mathrm{~min}$. Samples were visualized by SDS-PAGE and subsequent silver staining. PIN1-containing fractions were identified by western blotting with an anti-PIN1 monoclonal antibody as previously described (Blilou et al., 2005), and submitted for MS/MS analysis along with the nearest fraction of a higher protein concentration in which no PIN1 signal was detected.

\section{Fractionation of Arabidopsis membrane protein complexes by blue-native PAGE electrophoresis}

Microsomal pellets were resuspended in ice-cold $20 \mathrm{mM}$ bis-Tris pH 7.0 containing $500 \mu \mathrm{M} \varepsilon$ aminocaproic acid, $20 \mathrm{mM} \mathrm{NaCl}, 2 \mathrm{mM}$ EDTA and $10 \%$ glycerol and $0.6 \%$ dodecyl maltoside before centrifugation at $100,000 \times \mathrm{g}$ for $30 \mathrm{~min}$. Samples were diluted 1:1 with $750 \mu \mathrm{M}$ aminocaproic acid containing 5\% (w/v) coomassie G250. First dimension BN-PAGE proceeded according to Swamy et al. (2006). After separation, lanes were longitudinally cut into two 
strips. One strip was subjected to SDS-PAGE and western blotting as described above in order to identify regions which contained PIN1, the other was used for MS/MS. Corresponding strips, of a higher protein concentration in which no PIN1 signal was detected, were also submitted for MS/MS analysis.

\section{Mass spectrometry}

The respective gel parts were in-gel digested with trypsin. Resulting peptides were extracted from the gel parts and separated via HPLC (Shevchenko et al., 1996; Blagoev et al., 2004). For this analyses an UltiMate3000 HPLC system with Chromeleon software (Dionex, Germany) was used. Peptides were eluted with $300 \mathrm{nl} / \mathrm{min}$ flow rate and a gradient from $3 \%$ to $30 \%$ buffer A (80\% ( $\mathrm{v} / \mathrm{v})$ acetonitrile with $0.5 \%$ acetic acid) in 60 minutes on a self-packed C18 column (Reprosil material, $3 \mu \mathrm{m}$ particle size, packed in a fused silicate column with $75 \mu \mathrm{m}$ inner diameter, approximately $15 \mathrm{~cm}$ length and a nanospray emitter tip with an $8 \mu \mathrm{m}$ opening, New Objective, USA). Buffer A was water containing $0.5 \%(\mathrm{v} / \mathrm{v})$ acetic acid. The eluting peptides were transferred to a high-resolution mass spectrometer via a nanoelctrospray ion source with $5 \mathrm{kV}$ ioniziation current. Mass spectrometry was performed in positive ion mode on a LTQ-Orbitrap hybrid mass spectrometer (ThermoFisher Scientific, Germany) using the manufacturer's software. Peptides are identified via their exact masses and fragment ion patterns from tandem mass spectrometry fragment spectra (IDA mode). MASCOT server (Matrixscience Inc., UK) with the ncbi nr database, restricted to preen plants, was used for protein identification (Perkins et al., 1999).

\section{Plant lines}

The experiments were performed with the wild-type Arabidopsis (WT) ecotype Columbia 0 (Col-O) and the azg1 knockout t-DNA insertion lines azg1-1 (SAIL_114E03; Tessi et al., 2020), azg1-2 (GK-681A06; Tessi et al., 2020). Unless explicitly indicated, experiments used azg1-1. A double t-DNA insertion line azg1-1 x azg2-1, obtained by genetic crossing of azg1-1 and azg21 (SALK 000904; Tessi et al., 2020), was included in the analysis. For localization experiments the GUS lines ARR5pro:GUS, AZG1pro:GUS and azg1.1XARR5pro:GUS were used. TCSnpro:GFP was kindly provided by Dr. Müller (Zürcher, 2013).

\section{Generation of transgenic plants overexpressing AZG1}

AZG1 coding region was amplified from Arabidopsis root cDNA using Platinum Pfx DNA polymerase (Invitrogen) and the following primer combination: AZG1Smal-F (5'ATCCCGGGATGgAGCAACAGCAACAACAACAA-3) and AtAzg2Xbal-R (5'AGTCTAGACTAAACGGTAGTATCAATCTCACTA-3). The primers introduce the unique restriction sites Smal and Xbal at the $5^{\prime}$ and $3^{\prime}$ end, respectively. The amplified product was cloned into pCR-Blunt II-TOPO (Invitrogen) and sequenced using the PRISM fluorescent dye-terminator system (Applied Biosystems). The $1.4 \mathrm{~kb}$ fragment was subcloned into a modified version of the binary vector pGreen II (Fahnenstich et al., 2007) bearing the BASTA resistance gene, using the Smal and Xbal sites between the CaMV35S promoter and the Octopin-SynthetaseTerminator from the $\mathrm{PBinAR}$ vector. The resulting modified version of the $\mathrm{pGreenll}$ vector was 
called pGreenll-35S-nosBAR and the plasmid containing AZG1 was called p35S:AZG1. The plasmid p35S:AZG1 was introduced into Arabidopsis by Agrobacterium tumefaciens (GV3101) mediated transformation, using the vacuum infiltration method. Transformants were selected for resistance to BASTA. DNA was extracted from leaf material collected from selected plants and used for PCR analyses. Plants containing the transgene were transplanted and allowed to self. Seeds from the primary (T1) generation were sown and resultant T2 plants were subjected to another round of BASTA selection and characterization by means of PCR. The process was repeated to obtain non-segregating T3 transgenic lines. All further analyses were performed with homozygous T3 transgene plants.

\section{Generation of reporter lines}

A DNA fragment containing a $1713 \mathrm{bp}$ upstream and $179 \mathrm{bp}$ downstream of the AZG1 start codon was amplified by RT-PCR with the primers AZG1-GUS_f 5'CACCACACTGCGGCCTAAGAGAACAAACT-3' and AZG1-GUS_rev 5'GGTACCGCCACTTTCTTAACCATG-3'. This fragment was cloned into pGWB3, a gatewaycompatible binary vector designed for promoter-driven expression of the GUS gene (kindly provided by T. Nakagawa, Shimane University, Izumo, Japan). Cloning using gateway vectors was done using reagents and protocols from Invitrogen (Carlsbad, California, United States). The plasmid containing the chimeric AZG1pro:GUS gene was introduced into A. thaliana by Agrobacterium tumefaciens (GV3101) mediated transformation using the vacuum infiltration method. Transgenic lines were selected with Kanamycin and analysed for GUS activity.

To study the subcellular localization the U10pro:AZG1-GFP was generated. The AZG1 full coding sequence was cloned using Gateway cloning into pDONR207 entry vector and subcloned into pUBC-GW-GFP-DEST (Grefen et al., 2010). To drive the expression of AZG-GFP or AZG1-YFP with its native promoter, 1,5 kb of $A Z G 1$ promoter and the full coding sequence of an AZG-GFP or AZG1-YFP translational fusion were cloned in a single amplicon and introduced in pDONR207. The resulting AZG1pro:AZG1-YFP or AZG1pro:AZG1-YFP fusion was subcloned into the pMDC107 destination vector. All constructs were verified by sequencing.

\section{Plant growth conditions}

Plants were grown from seeds sown on Arabidopsis medium (AM) (2.2 g MS salts per litre, 2.5 $\mathrm{mM}$ MES pH 5.7, $15 \mathrm{mM}$ sucrose containing 1.3\% agar). After surface sterilization, seeds were incubated in dark overnight at $10^{\circ} \mathrm{C}$. All plates were then transferred into vertical position in a growth chamber (Versatile Environmental Test Chamber, Sanyo, Japan) with long-day conditions of $16 \mathrm{~h}$ light and $8 \mathrm{~h}$ dark at $22^{\circ} \mathrm{C}$.

Western blotting of PIN1 in plants proceeded according to Blilou et al. (2005). Two-day old seedlings were homogenised directly in Laemmli buffer $(100 \mu \mathrm{l}$ per $10 \mathrm{mg})$, centrifuged for 10 minutes at $24000 \times \mathrm{g}$ and loaded directly onto an SDS-PAGE gel. MG132 at $20 \mu \mathrm{M}$ and cyclohexamide $(50 \mu \mathrm{M})$ treatments were for 90 minutes immediately prior to homogenization. Root system phenotyping

To study the root system phenotype plant were grown vertically in Petri dishes. For general phenotyping under standard conditions MS 0,5 without Nitrogen + $20 \mathrm{mM} \mathrm{KNO}_{3}$ media was 
used. Plant were grown in 8-hour light 16-hour dark regime for 10 days after germination (dag). To study the effect of CK, plants were grown for 12 dag in $0.5 x$ MS with or without the addition of $200 \mathrm{nM}$ tZ.

For the study of root system reorganization, seedlings were grown in Petri dishes for 7 dag before the ablation of the distal $5 \mathrm{~mm}$ of the main root. Seedling were photographed 10 days after ablation. The same conditions were used to analyse the response of TCSnpro:GFP and AZG1pro:GUS after ablation. Root systems were measured and analyzed using ImageJ-FIJI.

\section{Immunolocalization}

Four-day old Arabidopsis seedlings were fixed twice under vacuum for 2 minutes in MTSB-T (1x MTSB, 4 \% formaldehyde, 1 \% Triton-X-100) followed by 40 minutes' incubation in the dark at room temperature. Afterwards all samples were washed with water and with MTSB-T and were transferred to an InsituPro pipetting robot (Intavis AG, Germany) with $650 \mu$ l buffer per well. The following treatments were then performed: 5 washes for 10 minutes in MTSB, 40 minutes' digestion in digestion solution ( $10.5 \mathrm{mg}$ macerozyme R-10 and $10.5 \mathrm{mg}$ driselase in $1 \mathrm{ml} \mathrm{H} \mathrm{H}_{2}$ ) were centrifuged for 4 minutes at $1000 \mathrm{rpm}$. The supernatant was added to $1 \mathrm{ml}$ $5 \mathrm{mM} \mathrm{MES}$ and made up to $7 \mathrm{ml}$ with $\mathrm{H}_{2} \mathrm{O}$ ), 5 washes for 12 minutes in MTSB, 2 incubations for 25 minutes in 2x MTSB, containing 20\% DMSO and 0.6\% NP-40, five washes for 10 minutes in MTSB, 1 hour incubation in MTSB containing $2 \%$ BSA, 5 hours incubation in MTSB containing $2 \%$ BSA containing either an anti-GFP (Roche) or an anti-PIN1 monoclonal antibody at $0.1 \%, 6$ washes for 12 minutes in MTSB, 4 hour incubation in MTSB containing $2 \%$ BSA and $0.5 \%$ Alexa-conjugated anti-mouse secondary antibody (Invitrogen), 9 washes for 15 minutes in MTSB, 7 washes for 15 minutes in deionized water. Coimmunolocalization was performed with a rabbit anti GFP primary antibody (Roche) and appropriate combination of Alexaconjugated secondary antibodies (Invitrogen).

\section{Callus generation}

Root segments of $5 \mathrm{~mm}$ were excised and incubated on AM medium containing 2,3 $\mu \mathrm{M} 2,4$ dichlorophenoxyacetic acid and $230 \mathrm{nM}$ kinetin. The resulting calli were propagated by placing freshly cut sections on new media plates every three weeks.

\section{GUS staining}

Plants were incubated for 20 minutes in $90 \%$ acetone $(a q)$ at room temperature before infiltration under vacuum for $30 \mathrm{~min}$ in $50 \mathrm{mM} \mathrm{NaPO}_{4}(\mathrm{pH} \mathrm{7,2),} 2 \mathrm{mM}$ Potassium-Ferrocyanide, $2 \mathrm{mM}$ Potassium-Ferricyanide, 0,2 \% Triton-X-100, $2 \mathrm{mM}$ X-Gluc. After incubation for $3 \mathrm{~h}$ in the dark plants were washed and sequentially incubated for 30 minutes in $70 \%, 80 \%, 90 \%$ and $100 \%$ ethanol. The stained plants were stored in $100 \%$ ethanol before mounting on glass slides with the SlowFade Antifade Kit (life technologies, USA). All GUS staining was observed and recorded with an AXIO Imager.A1 (Zeiss, Germany) using a Zeiss EC Plan-NEOFLUAR 10x/0,3 objective and Zeiss PLAN APOCHROMAT 20x/0.8 objective with use of Zeiss Zen 2 software. All pictures were taken with a Zeiss Axiocam 105 colour Camera. 


\section{iRoCS}

Propidium iodide-mediated staining of cell boundaries was performed in order to record 3D images for iRoCS analysis (Schmidt et al. 2014). Root tips of $1 \mathrm{~cm}$ were transferred to propidium iodide fixative solution, vacuum infiltration was applied twice for 2 minutes and roots were incubated for at least $12 \mathrm{~h}$ at $4^{\circ} \mathrm{C}$. Samples were sequentially washed in $80 \%, 50 \%$ and $30 \%$ ethanol, each for 5 minutes. Roots were then rinsed twice in water for 5 minutes and incubated in $20 \mathrm{mM} \mathrm{KPO}_{4}$ buffer ( $\mathrm{pH} 7.0$ ), $2 \mathrm{mM} \mathrm{NaCl}, 0.25 \mathrm{mM} \mathrm{CaCl}_{2}$ and $0.1 \mathrm{mg} / \mathrm{ml}$ amylase overnight at $37^{\circ} \mathrm{C}$ to remove starch from the root tip. The roots were rinsed twice in water for 5 minutes and then acidified by the addition of periodic acid to a concentration of $1 \%$ for 30 minutes at room temperature. Roots were again washed twice in water for 5 minutes and moved to Schiff reagent containing $0.1 \mathrm{mM}$ propidium iodide for 30 minutes. From this stage, roots were protected from light. The samples were rinsed twice in water for 5 minutes and then incubated in aqueous $73 \%(\mathrm{w} / \mathrm{v})$ chloral hydrate for $2 \mathrm{~h}$. Glycerol was added to $20 \%$ and roots were incubated overnight before mounting in in chloral hydrate solution containing 20 $\%$ glycerol.

Propidium iodide stained roots were detected by a LSM 510 META laser scanning microscope (Zeiss, Germany) and a 40x/1.3 DIC objective with oil immersion. Stacks of images were reconstructed into a three dimensional image as previously described (Schmidt et al., 2014) and automatically stitched by ZEN 2010 (Carl Zeiss Mircrolmaging GmbH).

Analysis of propidium iodide stained roots was performed by the intrinsic root coordinate system (iRoCS) according to Schmidt et al. (2014). After manual marking of the quiescent centre, the iRoCS Toolbox automatically detected cells and attached them to different cell layers in the root (epidermis with atrichoblasts and trichoblasts, cortex, endodermis, pericycle and vascular tissue) or designated them under- or over segmented. The marking by iRoCS was then manually corrected and under- as well as over-segmented cells were manually excluded from subsequent analysis. Data of cell parameters were analyzed with R-Studio.

\section{Cytokinin extraction, purification and quantitative analysis by UPLC-MS/MS}

Wild-type and azg1-1 plants were grown on MS plates or alternatively MS supplemented with $200 \mathrm{nM}$ tZ. Four independent biological samples made up of $1 \mathrm{~g}$ pooled rosette leaves were harvested after 26 days and kept frozen at $-80^{\circ} \mathrm{C}$. The procedure used for cytokinin analysis was a modification of the method described by Faiss et al. (1997). Freeze-dried plant material was homogenized in liquid nitrogen and extracted in ice-cold $70 \%(\mathrm{v} / \mathrm{v})$ ethanol. Deuteriumlabelled CK internal standards (Olchemim Ltd., Czech Republic) were added, each at 5 pmol per sample to check the recovery during purification and to validate the determination. The standards were $\left[{ }^{2} \mathrm{H} 5\right] \mathrm{tZ},\left[{ }^{2} \mathrm{H} 5\right] \mathrm{tZR},\left[{ }^{2} \mathrm{H} 5\right] \mathrm{tZ9G},\left[{ }^{2} \mathrm{H} 5\right] \mathrm{tZOG},\left[{ }^{2} \mathrm{H} 5\right] \mathrm{tZROG},\left[{ }^{2} \mathrm{H} 5\right] \mathrm{tZRMP},\left[{ }^{2} \mathrm{H} 3\right] \mathrm{DHZ}$, $\left[{ }^{2} \mathrm{H} 3\right] \mathrm{DHZR},\left[{ }^{2} \mathrm{H} 3\right] \mathrm{DHZ9G},\left[{ }^{2} \mathrm{H} 3\right] \mathrm{DHZOG},\left[{ }^{2} \mathrm{H} 3\right] \mathrm{DHZROG},\left[{ }^{2} \mathrm{H} 3\right] \mathrm{DHZRMP},\left[{ }^{2} \mathrm{H} 6\right] \mathrm{iP},\left[{ }^{2} \mathrm{H} 6\right] \mathrm{iPR}$, $\left[{ }^{2} \mathrm{H} 6\right] \mathrm{iP9G},\left[{ }^{2} \mathrm{H} 6\right] \mathrm{iPRMP},\left[{ }^{2} \mathrm{H} 7\right] \mathrm{BA},\left[{ }^{2} \mathrm{H} 7\right] \mathrm{BAR},\left[{ }^{2} \mathrm{H} 7\right] \mathrm{BA9G},\left[{ }^{2} \mathrm{H} 7\right] \mathrm{BARMP},\left[{ }^{15} \mathrm{~N} 4\right] \mathrm{mT}$, and $\left[{ }^{15} \mathrm{~N} 4\right] \mathrm{OT}$. All topolins were analysed using internal deuterium standards for $\left[{ }^{15} \mathrm{~N} 4\right] \mathrm{mT}$ and $\left[{ }^{15} \mathrm{~N} 4\right] \mathrm{oT}$ as no other labelled standards were available. Therefore, the values of other topolin metabolites may have an error load which originates from imperfect internal standardization. After $3 \mathrm{~h}$ extraction, the homogenate was centrifuged $\left(15,000 \mathrm{~g}\right.$ at $\left.4{ }^{\circ} \mathrm{C}\right)$ and the pellets were re- 
extracted. The combined supernatants were concentrated to approximately $1.0 \mathrm{ml}$ by rotary evaporation under vacuum at $35{ }^{\circ} \mathrm{C}$. The samples were diluted to $20 \mathrm{ml}$ with ammonium acetate buffer $(40 \mathrm{mM}, \mathrm{pH}$ 6.5). The extracts were purified using a combined (diethylamino)ethyl (DEAE)-Sephadex (Sigma-Aldrich, St. Louis, MA, USA) $(1.0 \times 5.0 \mathrm{~cm}$ )octadecylsilica $(0.5 \times 1.5 \mathrm{~cm})$ column and immunoaffinity chromatography (IAC) based on wide-range specific monoclonal antibodies against cytokinins (Faiss et al., 1997). This resulted in 3 fractions: (1) the free bases and 9-glycosides (fraction B), (2) a nucleotide fraction (NT) and (3) an O-glucoside fraction (OG). The metabolic eluates from the IAC columns were evaporated to dryness and dissolved in $20 \mu \mathrm{l}$ of the mobile phase used for quantitative analysis.

The cytokinin fractions were analysed by ultra-performance liquid chromatography (UPLC) (ACQUITY UPLCTM; Waters, Milford, MA, USA) linked to a Quattro microTM API (Waters, Milford, MA, USA) triple quadrupole mass spectrometer equipped with an electrospray interface. The purified samples were dissolved in $15 \mu \mathrm{MeOH} / \mathrm{H} 2 \mathrm{O}(30 / 70)$ and $10 \mu \mathrm{l}$ of each sample was injected onto a C18 reversed-phase column (Acquity UPLCTM is based on a combination of high pressure and small bridged ethylsiloxane/silica hybrid particles; BEH Shield RP18; $1.7 \mu \mathrm{m} ; 2.1 \times 150 \mathrm{~mm}$; Waters). The column was eluted with a linear gradient of $15 \mathrm{mM}$ ammonium formate $(\mathrm{pH} 4.0, \mathrm{~A})$ and methanol (B), with retention times for the monitored compounds ranging from 2.50 to $6.50 \mathrm{~min}$. The binary gradient $(0 \mathrm{~min}, 10 \% \mathrm{~B} ; 0-8$ min, $50 \%$ B) was applied with a flow-rate of $0.25 \mathrm{ml} / \mathrm{min}$ and a column temperature of $40^{\circ} \mathrm{C}$. Quantification was obtained by multiple reaction monitoring of $[\mathrm{M}+\mathrm{H}]+$ and the appropriate product ion. For selective MRM experiments, optimal conditions were as follows: capillary voltage $0.6 \mathrm{kV}$, source/desolvation gas temperature $100 / 350{ }^{\circ} \mathrm{C}$, cone/desolvation gas $2.0 / 550$ $\mathrm{L} / \mathrm{h}, \mathrm{LM} / \mathrm{HM}$ resolution 12.5 , ion energy $10.3 \mathrm{~V}$, ion energy $21.5 \mathrm{~V}$, entrance $2.0 \mathrm{~V}$, exit $2.0 \mathrm{~V}$, multiplier $650 \mathrm{eV}$. The dwell time, cone voltage, and collision energy in collision cell corresponding to exact diagnostic transition were optimized for each cytokinin. On the basis of retention time stability, the chromatographic run was split into eight retention windows. The dwell time of each MRM channel has been calculated to obtain 16 scan points per peak during which time the inter channel delay was $0.1 \mathrm{~s}$. In MRM mode, the limit of detection for most of cytokinins was below $5.0 \mathrm{fmol}$ and the linear range was at least five orders of magnitude. 


\section{Results}

\section{AZG1 interacts directly with PIN1}

PIN1-mediated polar auxin transport is an important factor which determines the size and shape of a root system. Once positioned correctly, auxin is likely to interact with a dense lattice of morphogenic signaling cascades. Prominent among these interacting signaling cascades are those stimulated by cytokinin, which affect auxin signaling and feed back onto auxin transport both transcriptionally and post-translationally (dello loio et al., 2008; Marhavý et al., 2014). In order to search for direct post-translational regulators of polar auxin transport, we searched for proteins which interacted with PIN1 in plasma membrane extracts from dark-grown Arabidopsis cell cultures. These membrane preparations were solubilized with $0.5 \%$ Triton X114; conditions which preserve the integrity of PIN1-containing membrane complexes. After the removal of detergent-insoluble membranes by centrifugation, the remaining soluble protein complexes were separated either according to their size (by blue-native PAGE) or their net charge (by isoelectrofocusing (IEF)-free flow electrophoresis (FFE)). FFE was chosen over capillary electrophoresis as it was able to maintain membrane protein solubility as complexes approached their isoelectric point. Fractions containing PIN1 were identified by western blotting and corresponded to a molecular mass of approximately $440 \mathrm{KDa}$ and a pl of 5.4 (Figure 1, A and B). Proteins of PIN1-containing fractions were identified by MS/MS spectrometry, and compared with the nearest fraction which did not contain PIN1. Proteins were considered to be putative PIN1 interactors if $i$ ) they were identified in both BN-PAGE and IEF-FFE experiments, ii) they were represented by more than one peptide in each experiment, and iii) were never identified in a control fraction. In total, peptides derived from 141 different proteins fulfilled these criteria after BN-PAGE fractionation, and from 133 proteins after IEFFFE fractionation. The proteins which were found in both groups were classified as potential PIN1 interactors, of which there were 33 (Figure $1 A$ and $B$ ). This report focuses on the physiological characterization of one of these proteins: a homolog of AzgA, a fungal purine transporter of the AZA-GUANINE RESISTANCE transporter family, named AZG1 (Mansfield et al., 2009; Tessi et al. 2020). AZG1 was identified by our MS/MS analysis with a total of seven peptides (Figure 1C).

In order to rule out an accidental co-migration of PIN1 and AZG1-containing protein complexes in both separation techniques, the proximity of the PIN1-AZG1 interaction was tested in an affinity-purification assay. Both PIN1-HA and a C-terminal AZG1-YFP fusion protein were transiently expressed in tobacco leaves, before microsomal proteins were solubilized with $1 \%$ dodecyl maltoside and AZG1-YFP was pulled-down with an immobilized anti-GFP antibody. Presence of PIN1-HA in the eluate, as determined by western blotting with an HRP-conjugated anti-HA antibody, was dependent on the presence of AZG1-YFP (Figure 1D), indicating a binary interaction. Not all of the 33 proteins which co-migrated with PIN1 in IEF-FFE and BN-PAGE were pulled down by PIN1 in this transient expression system. For example, two proteins with plausible functional links to auxin transport did not directly bind PIN1: SMT2, a sterol methyltransferase involved in cotyledon vein patterning (Carland et al., 2002) and DRP1A, a dynamin-like protein which has previously been shown to co-immunoprecipitate with PIN1, but is not thought to be a direct interactor (Mravec et al., 2011; Figure S1). 
A

Separation by complex size

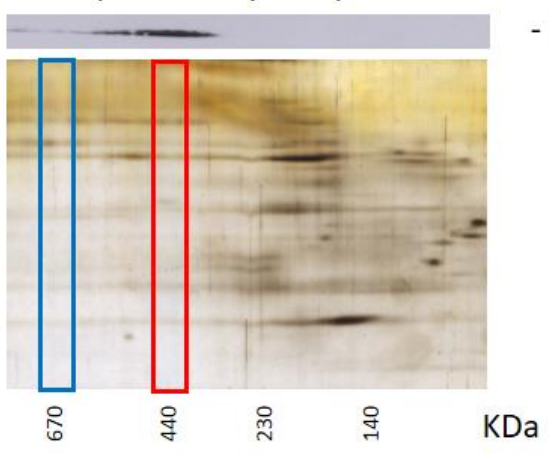

BN-PAGE

$\square-\square=141$ hits

B Separation by complex pl

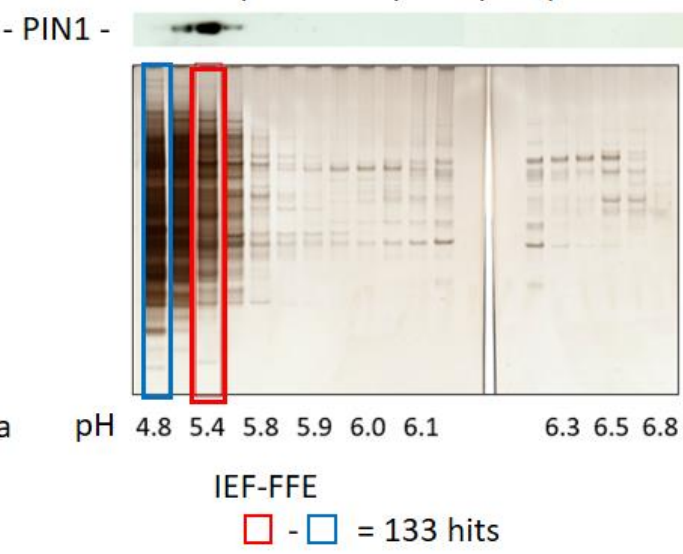

33 unique hits co-migrated with PIN1 in both experiments

C

D

AZG1

1 MEQQQQQQLP STTTRPKPKL LNRLNTYVGS SRVGKRFKLA ERNSTFTTEL

51 RAGTATFLTM AYILAVNASI LSDSGGTCSV SDCIPLCSNP AIEPSQCTGP

101 GLRLIQPDVS CKFNPVNPGY AACVEEIRKD LIVATVAASL IGCVIMGLMA

151 NLPLALAPGM GTNAYFAYTV VGFHGSGSIS YRTALAAVFI EGLIFLFISA

201 IGFRAKLAKL VPKPVRISSS AGIGLFLAFI GLQNNQGIGL VGYSPSTLVT

251 LAACPASSRI SLAPVITSAN GTVSLLAGGS VSGDIMCIHG RMESPTFWLG

301 IVGFVIIAYC LVKNVKGAMI YGIVFVTAVS WFRNTEVTAF PNTSAGDAAH

351 DYFKKIVDVH VIKHTAGALS FSGINKGHFW EALVTFLYVD ILDTTGTLYS

401 MARFAGFVDE KGDFAGQYFA FMSDASAIVI GSLLGTSPVT VFIESSTGIR

451 EGGRTGLTAI TVAVYFLLAM FFTPLLASIP AWAVGPPLIL VGVMMMKSVT

501 EIDWEDMREA IPAFVTMILM PLTYSVAYGL IGGIGSYVVL HLWDWGEEGL

551 VKLGFLKRKV KEEDNNNGVV KASEIDTTV

PIN1

1 MITAADFYHV MTAMVPLYVA MILAYGSVKW WKIFTPDQCS GINRFVALFA

51 VPLLSFHFIA ANNPYAMNLR FLAADSLOKV IVLSLLFLWC KLSRNGSLDW

101 TITLFSLSTL PNTLVMGIPL LKGMYGNFSG DLMVQIVVLQ CIIWYTLMLF

151 LFEYRGAKLL ISEQFPDTAG SIVSIHVDSD IMSLDGRQPL ETEAEIKEDG

201 KLHVTVRRSN ASRSDIYSRR SOGLSATPRP SNLTNAEIYS LOSSRNPTPR

251 GSSFNHTDFY SMMASGGGRN SNFGPGEAVF GSKGPTPRPS NYEEDGGPAK

301 PTAAGTAAGA GRFHYQSGGS GGGGGAHYPA PNPGMFSPNT GGGGGTAAKG

351 NAPVVGGKRQ DGNGRDLHMF VWSSSASPVS DVFGGGGGNH HADYSTATND

401 HOKDVKISVP OGNSNDNOYV EREEFSFGNK DDDSKVLATD GGNNISNKTT

451 QAKVMPPTSV MTRLILIMVW RKLIRNPNSY SSLFGITWSL ISFKWNIEMP

501 ALIAKSISIL SDAGLGMAMF SLGLFMALNP RIIACGNRRA AFAAAMRFVV

551 GPAVMLVASY AVGLRGVLLH VAIIQAALPQ GIVPFVFAKE YNVHPDILST

601 AVIFGMLIAL PITLLYYILL GL

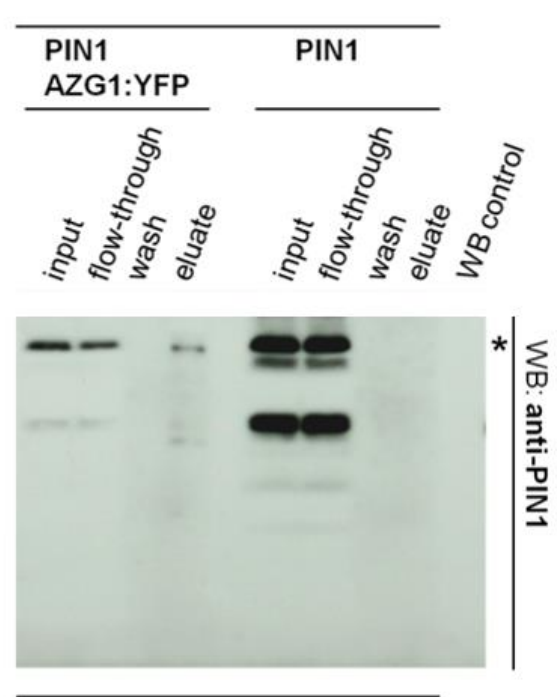

IP: anti-YFP

Figure 1 The identification of AZG1 as an interactor of PIN1. Arabidopsis microsomal protein comlexes were solubilized and separated by either (A) BN-PAGE or (B) IEF-FFE. Western blots used an anti-PIN1 primary antibody, total proteins ( $A$ and $B$, below) visualized with silver staining. Numbers of protein hits which were identified exclusively in PIN1-positive fractions (red boxes) and not in PIN1 negative fractions (blue boxes) for each method are given. C) Primary sequences of AZG1 and PIN1 indicating peptides identified in either BN-PAGE or IEF-FFE. D) Affinity purification of PIN1 using an anti-GFP antibody is dependent on the presence of a translational AZG1:YFP fusion. Proteins were extracted from tobacco mesophyll protoplasts transiently transformed with Arabidopsis coding sequences under the control of a 35S promoter. Asterisk indicates PIN1 signal. WB control shows untransformed cells. 


\section{AZG1 is a high affinity adenine importer, and CKs are strong competitors}

To better understand any potential physiological relevance of the AZG1-PIN1 interaction, we characterized the transport activity of AZG1. The AZG family has been primarily described in the filamentous Ascomycete Emericella nidulans. The gene family take its name from the capability of EnAZGA to transport not only purines (adenine, guanine and hypoxanthine) but also their toxic analogs aza-guanine and aza-adenine (Cecchetto, 2004). In plants, AZG1 has also previously been described as a cellular purine importer (Mansfield et al., 2009).

In order to further characterize the capacity of AZG1 to import purine in to the cell, we set up a heterologous model of adenine uptake in yeast. Cells expressing AZG1 displayed a linear accumulation of radiolabeled adenine for the first three minutes of incubation; the accumulation rate was more than 10 -fold higher than untransformed control cells, consistent with the results reported by Mansfield et al. (2009) (Figure 2A). The rate of adenine import was saturable by increasing substrate concentration. The deduced Michaelis-Menten kinetic parameters indicate a $K_{m}$ of $1.62 \pm 0.21 \mu \mathrm{M}$ and a $V_{\max }$ of $16.2 \pm 0.28 \mathrm{pmol} / 10^{6}$ cells $/$ minute (Figure 2B). We therefore conclude that AZG1 is a high-affinity adenine transporter. To our knowledge, the $K_{m}$ of AZG1 for adenine makes it the highest affinity purine transporter reported to date.

The substrate specificity of AZG1 was investigated by determining the ability of a range of compounds to inhibit AZG1-mediated ${ }^{14} \mathrm{C}$-adenine uptake in yeast cells when present in a 10 fold excess (Figure $2 \mathrm{C}$ ). Adenine, guanine and hypoxanthine were all strong competitors. Less effective were cytosine (a substrate for plant purine transporters, PUPs; Burkle et al., 2003; Zürcher et al., 2016), caffeine (which is also transported by PUPs), adenosine (a substrate of equilibrative nucleoside transporters, ENTs; Möhlmann et al., 2001), as well as xanthine, uric acid, uracil and allantoin (substrates for NATs; Maurino, et al., 2006; Niopek-Witz et al., 2014, and Ureide Permeases, UPS; Desimone et al., 2002); all only had a marginal effect on the transport of ${ }^{14} \mathrm{C}$-adenine. 8-Azaguanine strongly inhibited the AZG1-mediated cellular import of adenine, consistent with the resistance phenotype of overexpression and loss-of-function lines (Mansfield et al., 2009; Tessi et al., 2020). In general, the range of compounds which inhibited AZG1-mediated adenine accumulation was similar to that of EnAZGA (Cecchetto et al., 2004) suggesting a conserved protein function for eukaryotic AZG transporters. 
A

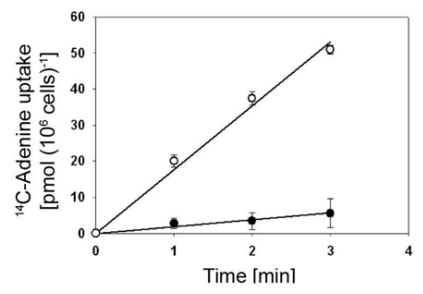

D

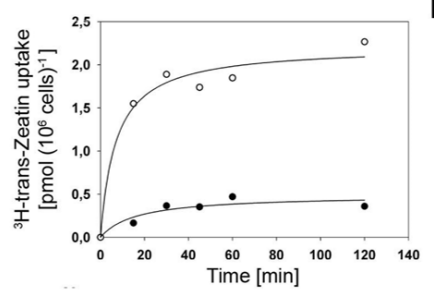

$\mathrm{F}$

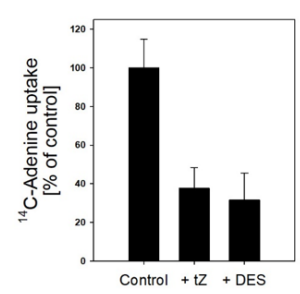

B

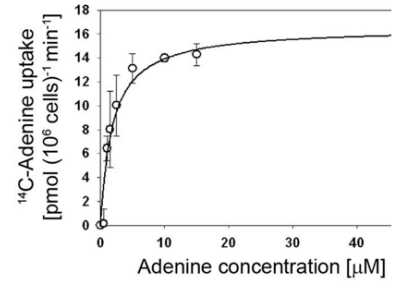

$\mathrm{E}$

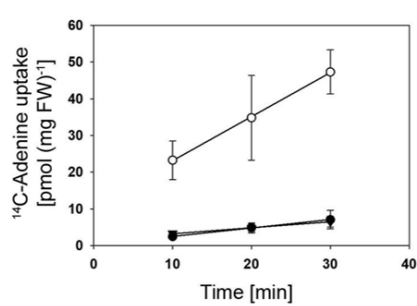

G

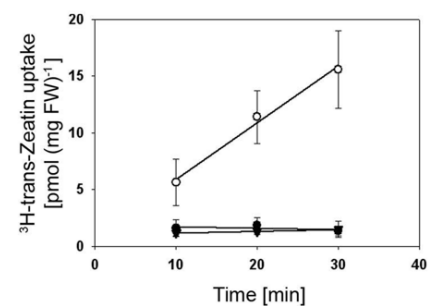

C

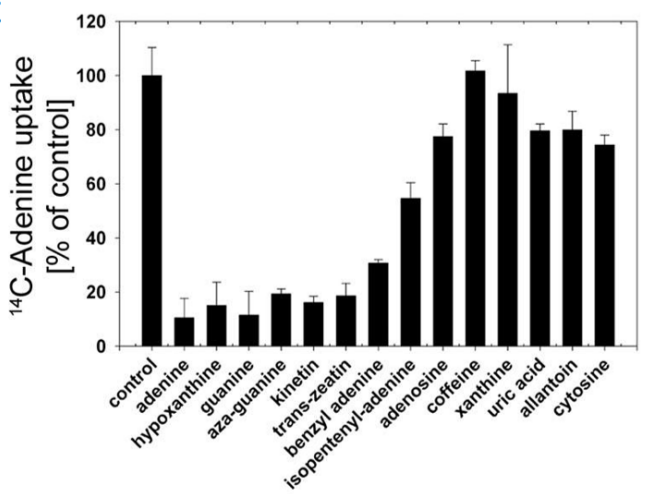

Figure 2 A) Yeast cells transformed with pESC-AZG1 (open circles) or with the empty vector (closed circles) were assayed for ${ }^{14} \mathrm{C}$-adenine uptake at $20 \mu \mathrm{M}$ substrate concentration and $\mathrm{pH}$ 4. B) Concentration-dependent AZG1mediated adenine uptake. Rates were calculated after the subtraction of background uptake rates (empty vector). C) AZG1-mediated uptake of ${ }^{14} \mathrm{C}$-adenine $(20 \mu \mathrm{M}$ ) was determined in the presence of 10 -fold excess (200 $\mu \mathrm{M})$ of unlabelled compounds. Stated values have been normalized to uptake rates in the absence of competitors. D) Yeast cells transformed with pESC-AZG1 (open circles) or with the empty vector (closed circles) were assayed for ${ }^{3} \mathrm{H}$-trans-zeatin (tZ) uptake at $20 \mu \mathrm{M}$ substrate concentration. (E) Uptake of ${ }^{14} \mathrm{C}$-adenine (E) or ${ }^{3} \mathrm{H}$-tZ. F) Proton dependence of ${ }^{14} \mathrm{C}$-adenine uptake and competition with tz. ${ }^{14} \mathrm{C}$-Adenine $(25 \mu \mathrm{M})$ net uptake by 35Spro:AZG1 plants as a percentage of wild type control. Also given are values in the presence of either diethylstilbestrol (DES) or $250 \mu \mathrm{M}$ tZ. (G) into 14-day-old Arabidopsis seedlings. WT (closed circles), azg1 (triangles) and 35S:AZG1-1 (open circles) seedlings were incubated with $20 \mu \mathrm{M}{ }^{14} \mathrm{C}$-adenine for the indicated time All experiments were run for 30 minutes. Values given are averages of four experiments, bars indicate standard error. Values represent the mean \pm SD of three independent experiments.

\section{AZG1 is a cytokinin importer}

Cytokinins form a class of plant growth regulators which share structural similarities with purines. Remarkably, aside from other purines, different cytokinin where the strongest inhibitors of AZG1-mediated cellular adenine import. In this respect, $t Z$ and kinetin were highly effective competitors, followed by benzyl-adenine and pentenyl-adenine (Figure $2 \mathrm{C}$ ). These data indicated that AZG1 most likely use these cytokinins as substrates. Therefore, we next measured the capacity of AZG1 to transport radiolabeled tZ. In this case, uptake of the maximal amount of label was reached after a few seconds, at which point a significant difference in the amount of accumulated radioactive $t Z$ was observed between control and AZG1-expressing cells (Figure 2D).

To determine whether AZG1 was able to transport physiologically relevant purines in planta, 14-day-old seedlings were incubated with ${ }^{14} \mathrm{C}$-adenine. Both WT and azg1-1 loss-of-function 
seedlings showed a linear uptake over 30 minutes, but no significant differences in the uptake rates could be observed (Figure $2 \mathrm{E}$ ). It is possible that the accumulation of ${ }^{14} \mathrm{C}$-adenine in WT and loss-of-function seedlings was primarily mediated by proteins other than AZG1. In contrast, the transport rate of ${ }^{14} \mathrm{C}$-adenine in 35Spro:AZG1 seedlings was at least five times higher than that which was measured in WT plants (Figure 2E).

To test whether AZG1 was able to transport CK in planta, the yeast competitive uptake experiment was replicated in seedlings. Here, the transport of ${ }^{14} \mathrm{C}$-adenine in 35 Spro:AZG1 seedlings was strongly inhibited by the addition of a 10 -fold excess of unlabeled $t Z$, or after disruption of proton gradients by the addition of diethylstilbestrol (Figure 2F). These data suggest that $\mathrm{tZ}$ can compete with adenine for AZG1-dependent transport in seedlings.

To test whether cytokinins were being taken up into the cytosol, or were merely competing with adenine for membrane binding sites and not being transported, the capacity of AZG1 for cytokinin transport was addressed by measuring the uptake of ${ }^{3} \mathrm{H}$-tZ in 14-day-old seedlings. As was seen in the transport studies with ${ }^{14} \mathrm{C}$-adenine, WT and loss-of-function seedlings showed no significant differences in uptake, but AZG1 overexpressors exhibited an enhanced uptake capacity (Figure 2G). The uptake rate of ${ }^{3} \mathrm{H}$-tZ by $\mathrm{AZG1}$ overexpressors was directly proportional to incubation time for at least 30 minutes and its accumulation rate was approximately six times higher than was measured in WT plants. These results demonstrate that AZG1 is able to drive cellular $\mathrm{tZ}$ uptake in planta.

We next tested whether the loss of AZG1 function altered the profile of cytokinin metabolites in the plant after exogenous treatment with tZ. Three-week old WT and AZG1 plants were grown in the presence of $200 \mathrm{nM}$ tZ before rosette leaves were harvested and their cytokinin content measured. Consistent with the hypothesis that AZG1 functions as a cytokinin uptake protein in plants we observed a decrease in all tZ derivatives measured in the AZG1 plants when compared to the WT (Figure S2).

\section{AZG1 co-localizes with PIN1 in the plasma membrane of Arabidopsis root cells}

PIN1 is polarly localized to the plasma membrane, from where it is thought continuously to recycle to endosomal compartments. In the root apical meristem (RAM), PIN1 is localized to the rootward face of stele cells, and is especially prominent in protoxylem pole cells. In order to ascertain whether AZG1 shares an expression domain with PIN1, plants were constructed in which the expression of AZG1-YFP was driven by its native promoter. When localized with an anti-GFP polyclonal antibody, AZG1-YFP was seen to localize to LR cap cells, epidermal cells and stele cells of the RAM, but was seen most distinctly in protophloem cells (Figure $3 \mathrm{~A}$ and B). AZG1 was also continuously expressed from the heart stage of the developing embryonic root, where its expression domain became gradually more refined through the torpedo stage to vascular cells in the mature embryonic seedling (Figure $3 \mathrm{C}-\mathrm{E}$ ). Visualization of AZG1 after transient expression of in Arabidopsis protoplasts and roots with a $p U 10: A Z G 1-G F P$ construct indicated it also resided in the plasma membrane (Figure 3 F-K). 

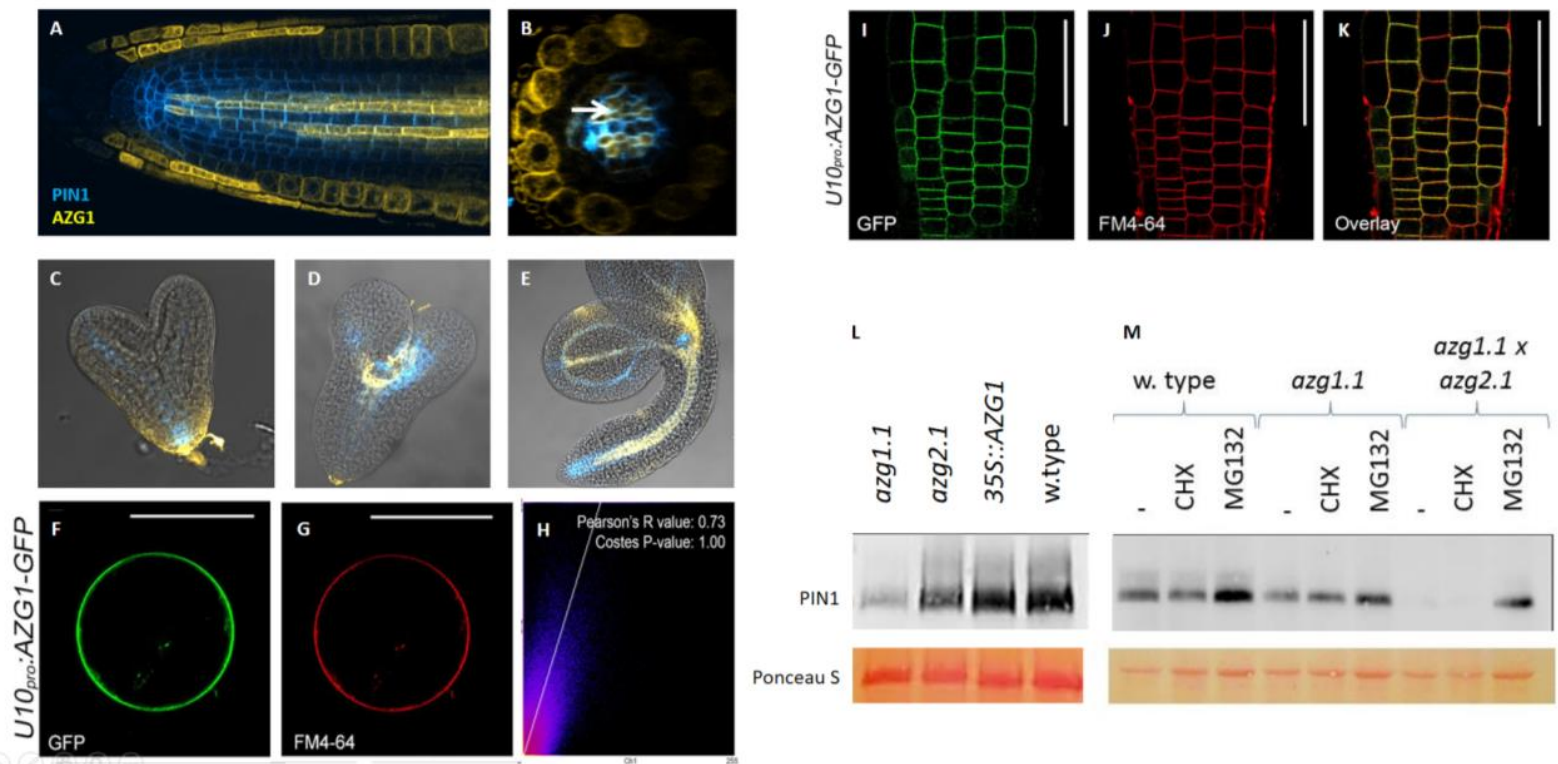

Figure 3 AZG1 stabilizes PIN1 in co-expression domains. Coimmunolocalization of AZG1:GFP (yellow) and PIN1 (blue) in A) the root apical meristem, B) the root apical meristem in radial section, Embryos at C) heart stage, D) torpedo stage, and E) mature stage. Subcellular localization of AZG1. F) Transient expression of $p$ U10:AZG1-GFP construction in Arabidopsis root protoplasts compared to G) FM4-64 staining. H) Co-localization analysis of AZG1GFP and FM4-64 marker of figures I and J performed using Coloc2 (FIJI). I) AZG1-GFP fusion under the control of the U10 promoter in epidermis cells of the meristematic zone compared to J) FM4-64 staining, and $\mathrm{K}$ ) with the signals overlayed. Scale bars represent (F and G) $10 \mu \mathrm{m}$ and (I-K) $50 \mu \mathrm{m}$. L) The relative amounts of PIN1 in 2-day old Arabidopsis seedlings. M) The relative amounts of PIN1 in 2-day old Arabidopsis seedlings after treatment with inhibitors of protein translation (CHX) and degradation (MG132). Loading control shows PVDF membranes stains with Ponceau S. Western blots were performed with an anti-PIN1 monoclonal antibody.

RT-PCR analysis revealed that $A Z G 1$ was expressed in all tissues tested, with flowers and roots showing the highest amounts of transcript (Figure S3A). Expression of pAZG1:GUS was also observed in most tissues (Figure 4); primary root and LR apical meristems displayed distinct and different pAZG1:GUS staining patterns (Figure 4I-L). In seedlings the GUS staining broadened after 4 hours treatment with $200 \mathrm{nM}$ tZ (Figure $4 \mathrm{M}$ and $\mathrm{N}$ ). In the primary RAM, GUS staining was relatively evenly distributed, but the lateral RAM showed a narrower distribution of staining which was focused around the quiescent center (QC). In both types of root, $C K$ induced $p A Z G 1$-dependent gene expression. A $90^{\circ}$ rotation of plates induced $p A Z G$ dependent gene expression in peripheral cells of the apical meristem of LRs (Figure 40 and $4 P)$, but the gravitropic response of $A Z G 1$ loss of function plants was only mildly affected (Figure S3B). 


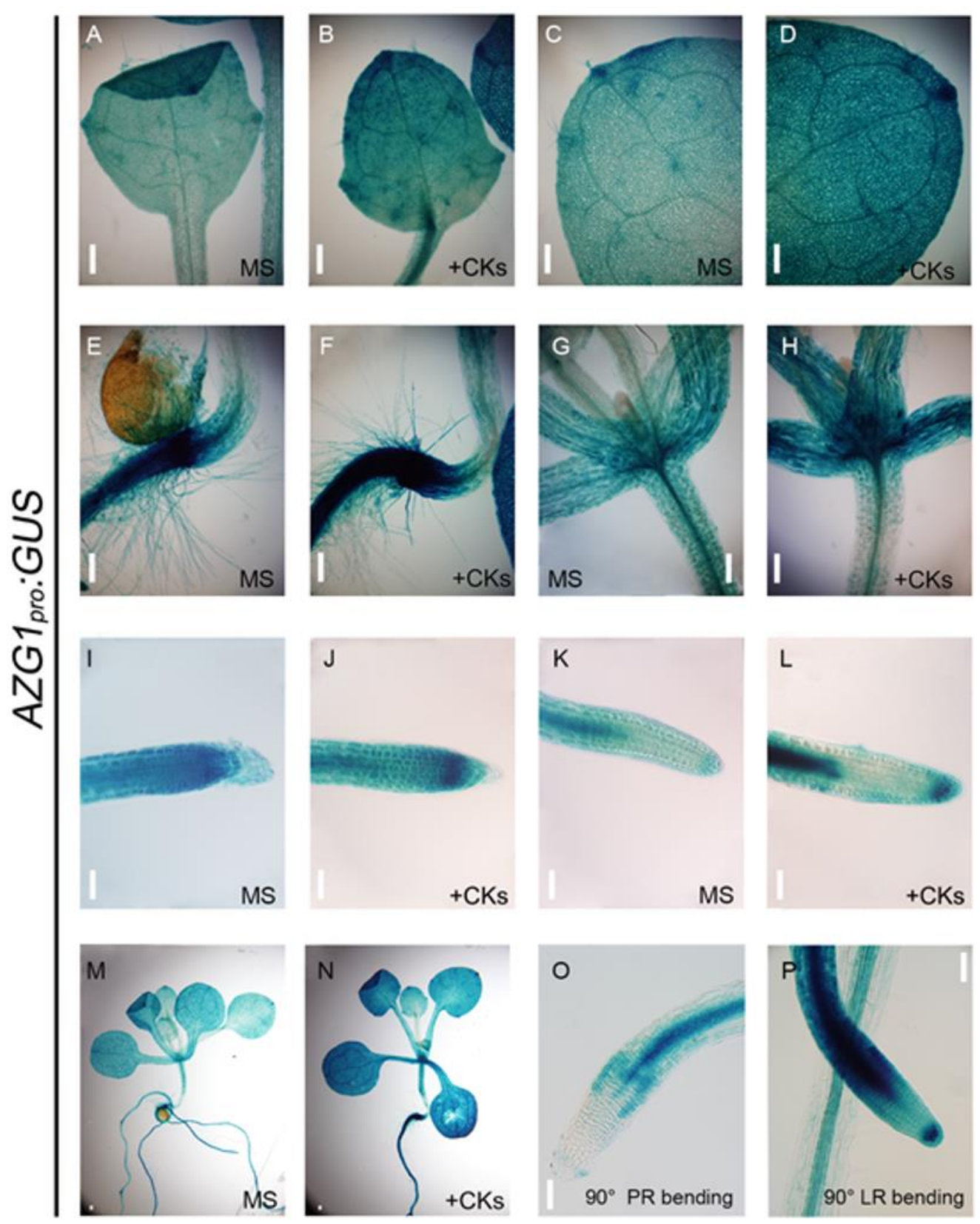

Figure 4 AZG1pro:GUS expression in Arabidopsis. Expression of GUS reporter gene under the control of an AZG1 promoter in (A-D) leaves, (E-F) transition zone, (G-H) hypocotyls and shoot apical meristem, (I-J) primary root apical meristem, (K-L) secondary root apical meristem, (M-N) entire seedling and after a $90^{\circ}$ rotation of $(\mathrm{O})$ the primary root $(P R)$ or $(P)$ a lateral root (LR). The legend $+C K$ indicates a $4 \mathrm{~h}$ incubation with $200 \mathrm{nM} \mathrm{tZ}$. Scale bar $=100 \mu \mathrm{m}$.

\section{AZG1 stabilises PIN1}

During LR organogenesis, cytokinin redirects PIN1 for degradation (Marhavý et al., 2011; Marhavý et al., 2014). Though the mechanism of this regulation is known to involve posttranslational processes, its exact nature remains unclear. As a protein which simultaneously binds PIN1 and cytokinin in the plasma membrane, AZG1 is a potential point at which this control could be effected. The genomes of flowering plants encode two AZG homologs, named AZG1 and AZG2. To test whether either protein affected PIN1 stability in Arabidopsis, the 
relative amount of PIN1 was visualized in three-day-old seedlings of WT, azg1-1, and azg1-1 x azg2-1 plants. Immunolocalization of PIN1 in azg1-1 and azg1-1 x azg2.1 genotypes indicated a progressive contraction of the PIN1 expression domain (Figure S4), and western blot analysis confirmed that two-day old azg1-1, azg2-1 and azg1-1 x azg2-1 seedlings contained less PIN1 than did WT seedlings of the same age (Figure 3L). Overexpression of AZG1 using the 35S promoter had no observable effect on PIN1 abundance (Figure 3L). Blocking proteasomemediated protein degradation by treating plants with MG132 for 90 minutes resulted in the reappearance of PIN1 in azg1-1 x azg2-1 seedlings (Figure 3M). We therefore conclude that AZG1 and AZG2 act together to stabilize PIN1. Blocking protein synthesis in seedlings by treating them for 90 minutes with cyclohexamide did not visibly affect the amount of PIN1 in WT plants, suggesting that the protein was stable in the membrane over this time period. Over the same period, cyclohexamide treatment had no effect on PIN1 abundance in azg1-1 or in azg1-1 x azg2-1.

\section{Cytokinin responsiveness during root growth and cell differentiation}

CK exerts a strong and pervasive influence over RSA (Laplaze et al.,2007; Argueso et al., 2009; Werner et al., 2010). In accordance with this, the developing azg1-1 root appeared to be particularly sensitive to environmental cues such as the combination of high nitrate $(20 \mathrm{mM}$ $\mathrm{KNO}_{3}$ ) and short photoperiod ( $8 \mathrm{~h} / 16 \mathrm{~h}$ light/dark), showing a longer primary root and denser LRs when compared to WT (Figure $5 \mathrm{~A}$ and $\mathrm{B}$ ). These differences were more noticeable in the presence of exogenous $\mathrm{tZ}$ (Figure $5 \mathrm{C}-\mathrm{F}$ ). 35Spro:AZG1 showed an increased sensitivity to tZ (Figure $5 \mathrm{C}-\mathrm{F}$ ). Primary root growth inhibition by $\mathrm{tZ}$ was restored in a complementation line in the azg1-2 genetic background (Figure 5F). These results are consistent with endogenous AZG1 increasing the permeability of plasma membranes to CK in developing LR primordia and within the Arabidopsis RAM.

The delicate balance between cell division and cell fate acquisition in is under the influence of diverse signaling molecules (van den Berg et al., 1997; Xu et al., 2006). Among these, the balance of auxin and cytokinin is again prominent in determining cells' developmental fate, with auxin promoting the formation of roots and cytokinin promoting the formation of shoots (dello loio et al., 2008; Murashige and Skoog, 1962). We therefore prepared de-differentiated callus cultures, predicting that azg1-1 calli would be less sensitive to cytokinin than WT calluses, and therefore more likely to develop roots when treated with kinetin. When treated with media supplemented with kinetin at concentrations of between $230 \mathrm{nM}$ and $3.7 \mu \mathrm{M}$, between 50 and $80 \%$ of WT root explants grew leaves (Figure S5). In contrast, azg1 root explants grown on $230 \mathrm{nM}$ kinetin consistently failed to develop aerial tissues. Kinetin at 460 $\mathrm{nM}$ was able to stimulate leaf development in 9\% of azg1-1 calli, with a maximum rate of leaf development observed at $930 \mathrm{nM}$ kinetin (Figure S5). We therefore conclude that in WT root explants, AZG1 serves to increase the permeability of the plasma membrane to an inward flux of kinetin.

Observations of the RAM after ablation have previously yielded valuable insights into the way in which relevant signals interact (Xu et al., 2006; Sauer, 2006; Rosquete, 2013). To integrate the dynamics of AZG1 expression and its role in CK signaling into RAM signaling programs, we 
excised the primary RAM of Arabidopsis seedlings and observed the response of AZG1pro:GUS and TCSnpro:GFP reporters. After the ablation of the RAM, a decrease in AZG1pro:GUS expression was observed both in the main root and in LRs (Figure S6A). Similarly, TCSnpro:GFP expression in the stele was down-regulated following RAM ablation, and was barely detectable in non-vascular tissues (Figure S6B). To understand further the causal relationship between changes in the distribution of CK signaling maxima and AZG1 transport activity, we excised the RAM of seven-day old azg1-1 plants. Nine days later, azg1-1 plants developed shorter LRs when compared to WT plants (Figure 5G). These data suggest that AZG1 plays a role in the remobilization of CK to sites of lateral root development during root system reorganization after loss of the primary RAM.
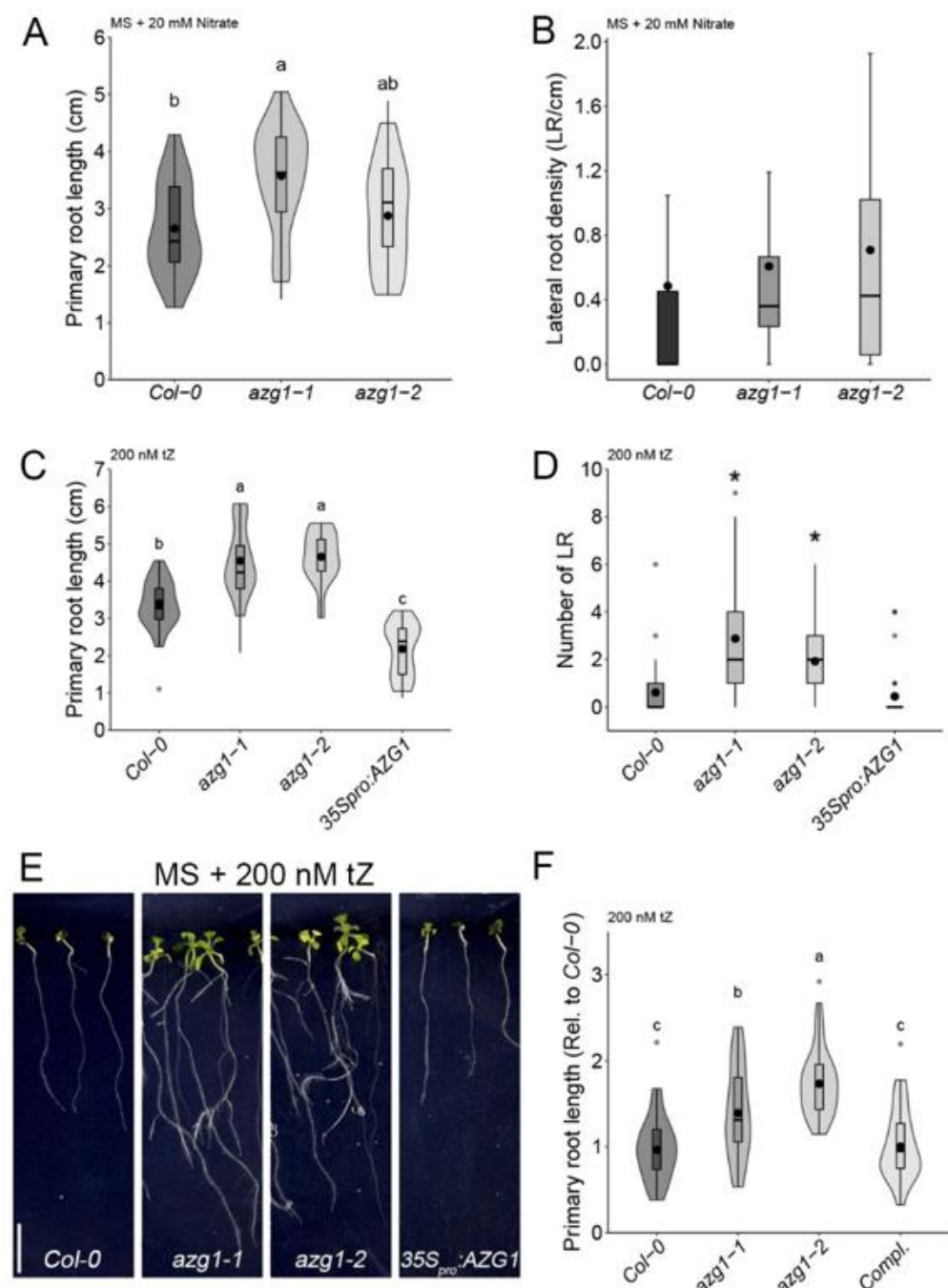

$\mathrm{MS}+200 \mathrm{nM} \mathrm{tZ}$

F

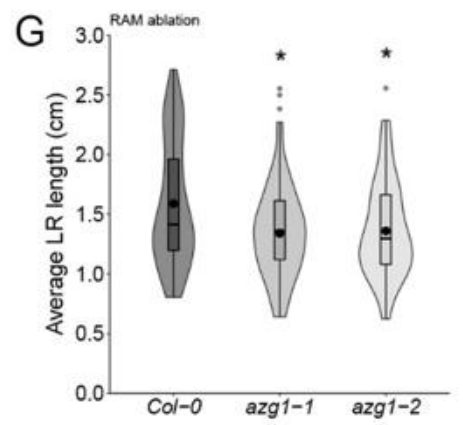

$\mathrm{H}$
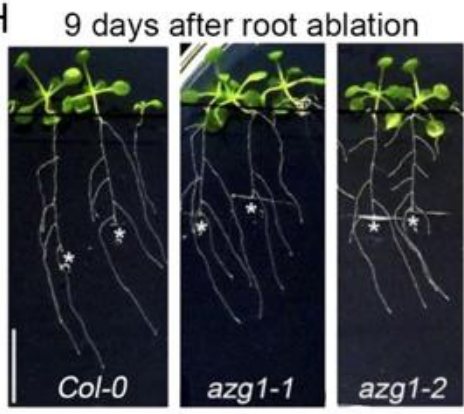
Figure 5 Root phenotype of azg1 mutant lines. (A) Primary root length and (B) LR density of azg1-1 and azg1-2 growing in $0.5 \mathrm{x} \mathrm{MS}$ containing $20 \mathrm{mM} \mathrm{KNO}_{3}$ as their sole source of nitrogen. Response of azg1 mutants root architecture without (C) and in the presence of ( $D$ and $E$ ) exogenous $200 \mathrm{nM}$ tZ treatment with respect to (D) primary root length and (E) number of emerged LR per plant. F) Complementation of primary root length phenotype in the presence of $200 \mathrm{nM}$ tZ (azg1-2 line transformed and selected in homozygotes for AZG1pro:AZG1-GFP. G) Representative plants of Col-0, azg1-1, azg1-2 and 35Spro:AZG1 grown in presence of $200 \mathrm{nM}$ tZ (H) Representative plants after root apical meristem removal. Scale bars represent $1 \mathrm{~cm}$. Asterisk shows significant differences determined by ANOVA test, followed by a Duncan multiple range test $(p<0.05$; (AB) $n W t=31, n a z g 1-1=41$, nazg1-2=34; (C) $n W t=27$, nazg1-1=28, nazg1-2=27, n35Spro:AZG1=30; (F) nWt=35, nazg1-1=32, nazg1-2=27, nCompl.=36) or (D and G) Kruskal-Wallis test, followed by a Wilcox multiple range test ((D) $\mathrm{p}<0.01 ; \mathrm{nWt}=27, \mathrm{nazg1-1}=28, \mathrm{nazg1-2}=27, \mathrm{n35Spro:AZG1=30;(G)} \mathrm{p}<0.05 ; \mathrm{nWt}=54$, nazg1-1=58, nazg1$2=34)$.

\section{Cytokinin signaling in the RAM and lack of RAM phenotype}

To test the hypothesis that AZG1 drives a cytokinin signaling maximum in the RAM, plants expressing the ARR5pro:GUS reporter were crossed into both azg1-1 and 35Spro:AZG1 plants. In all cases, ARR5-driven GUS staining was localized to columella cells (Figure 6). The distribution of staining was narrower in azg1-1 plants when compared to WT, where staining was also observed in stele stem cells (Figure 6, A and D). In contrast, 35Spro:AZG1 plants displayed a broader distribution of GUS-dependent staining, with coloration being observed in stele cells of the meristematic division zone (Figure 6, G). A similar observation was also made in two independent insertion lines of the TCSnpro:GFP reporter in the azg1-1 background. Defective CK signalling has been reported in the stele region in CK-deficient mutants log3/log 4 and Ihw mutants (Ohashi-Ito et al., 2014). In azg1-1 lines, CK signalling in stele cells of the root meristematic zone was heavily repressed (Figure S7 A-B).

ARR5pro:GUS-dependent staining in seedlings was cytokinin dependent after treatment with $100 \mathrm{nM}$ tZ for either 3 hours (Figure 6, B, E, H) or 9 hours (Figure 6, C, F, I). In tZ-treated 35Spro:AZG1 plants, the cytokinin-dependent signaling maximum extended through the vascular cells of the division zone and into those of the elongation zone (Figure $6 \mathrm{H}$ and I).

To test the effect on the structure of the RAM of losing AZG1 function, the cellular architecture of populations of $A Z G 1$ and WT roots were compared. To do this, iRoCS, a pipeline which assigns root cells $3 \mathrm{D}$ coordinates relative to the root's central spline, was used. Surprisingly, and despite a difference in the distribution of cytokinin-dependent signaling maxima, no significant difference between the cellular structures of the azg1-1 and WT RAM was observed (Figure S8). 


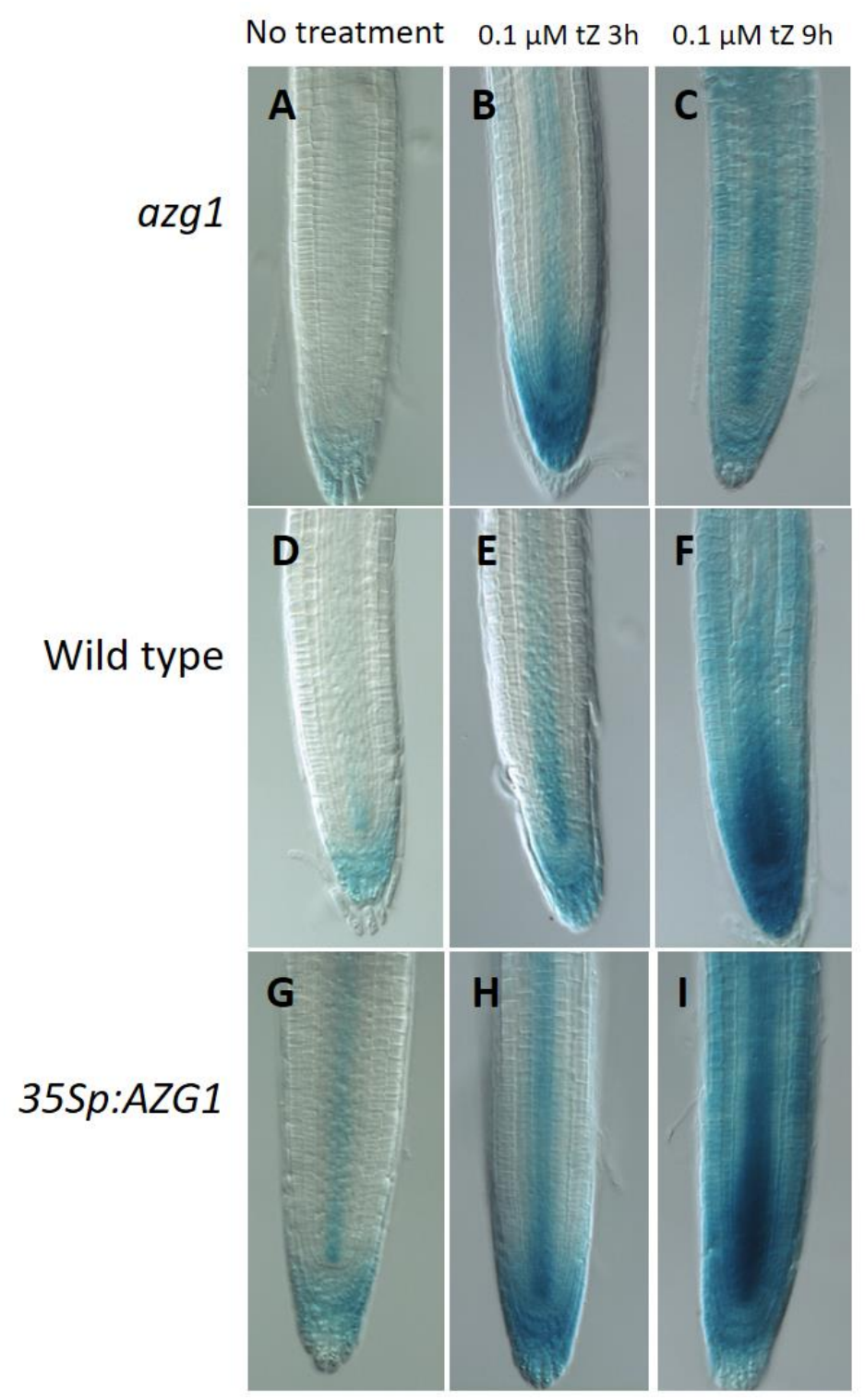

Figure 6 AZG1 drives cytokinin signaling in the RAM. A) Localization in Arabidopsis roots of ARR5pro:GUS expression in azg1-1 (A-C), WT (D-F), or 35Spro:AZG1 (G-I) genetic backgrounds. Roots were either untreated (A, $D$, and $G)$, or treated with $100 \mathrm{nM}$ tZ for either 3 hours (B, E and $H$ ) or 9 hours (C, F and I).

\section{AZG1 expression is induced by $\mathrm{NaCl}$}

Cytokinin influences plants' ability to tolerate $\mathrm{NaCl}$ in the soil (O'Brien and Benková 2013). We therefore next investigated whether AZG proteins mediated changes in the architecture of the root system, especially those in response to increased salinity or decreased water availability. For this purpose, seven day old WT and azg1-1 $\times$ azg2-1 plants were transferred to $1 / 2 \mathrm{MS}$ medium containing either 25 or $50 \mathrm{mM} \mathrm{NaCl}$, and the density of fully emerged LRs was measured after a further ten days of growth. In order to parse the effects of decreased water availability and the presence of $\mathrm{NaCl}$, the experiment was also conducted in the presence of either 50 or $100 \mathrm{mM}$ mannitol.

In the absence of mannitol WT plants, LR density decreased as a function of increasing $\mathrm{NaCl}$ concentration, whereas no significant difference was measured in azg1-1x azg2-1 roots (Figure 7A). The effect of the azg1-1 x azg2-1 mutations on LR density depended on the salt 
concentration: in the absence of $\mathrm{NaCl}$, LR density was lower in azg1-1 x azg2-1 than in WT, but at $50 \mathrm{mM} \mathrm{NaCl}$ it was higher (Figure 7A).

Supplementing media with $\mathrm{NaCl}$ has two simultaneous effects: those due to sodium ions (sodicity), and those due to a simultaneous reduction in water availability. In order to parse these effects, plants were transferred to plates supplemented with mannitol in order to alter sodicity and water availability independently. In the presence of $50 \mathrm{mM}$ mannitol (a medium with the same osmotic strength as $25 \mathrm{mM} \mathrm{NaCl}$ ), LR density was inhibited by the addition of $\mathrm{NaCl}$ at either $25 \mathrm{mM}$ and 50mM NaCl in WT and azg1-1 $x$ azg2-1 (Figure 7B). This effect was also observed at $100 \mathrm{mM}$ mannitol, with LR density also being inhibited by $\mathrm{NaCl}$ in a similar manner in both WT and azg1-1 $x$ azg2-1 plants (Figure 7C).

By comparing $\mathrm{LR}$ density at similar osmotic pressures, and simultaneously at different $\mathrm{NaCl}$ concentrations, (50 mM NaCl (see Figure 7A); $25 \mathrm{mM} \mathrm{NaCl}+50 \mathrm{mM}$ mannitol (see Figure 7B); $100 \mathrm{mM}$ mannitol (see Figure $7 \mathrm{C}$ )), we were able to compare the effects of sodicity and drought. When osmotic pressure was kept constant by mannitol in this way, the presence of $\mathrm{NaCl}$ lowered LR density in WT plants, but increased it in azg1-1 x azg2-1. Only the strength but not the direction of the root growth response to mannitol and/or $\mathrm{NaCl}$ was affected when WT and azg1-1 $x$ azg2-1 plants were compared (Figure 7 D-F). We therefore conclude that the ability of WT roots to decrease LR density in response to $\mathrm{NaCl}$ requires AZG proteins. This result identifies AZG1 as a potentially important factor in the response of the LR system to local increases in $\mathrm{NaCl}$ concentration in the soil. Such an effect was not observed when considering main root length (Figure 7D-F).

A

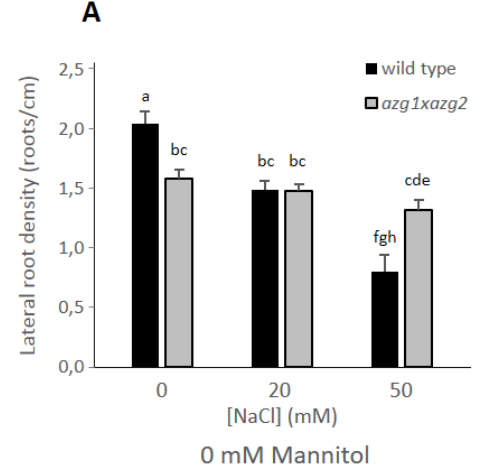

D

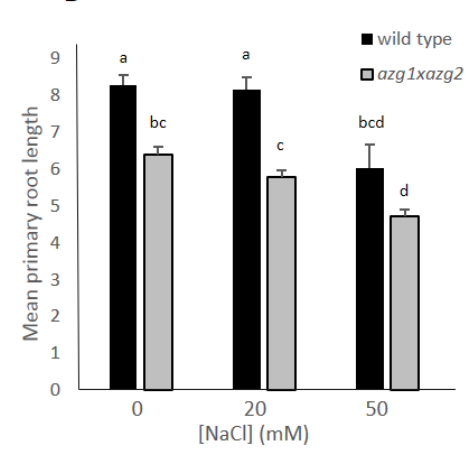

$0 \mathrm{mM}$ Mannitol
B

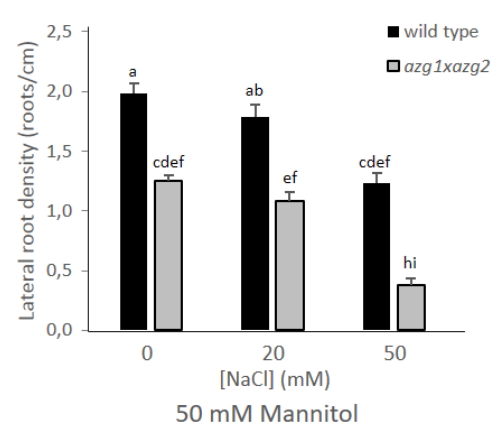

E

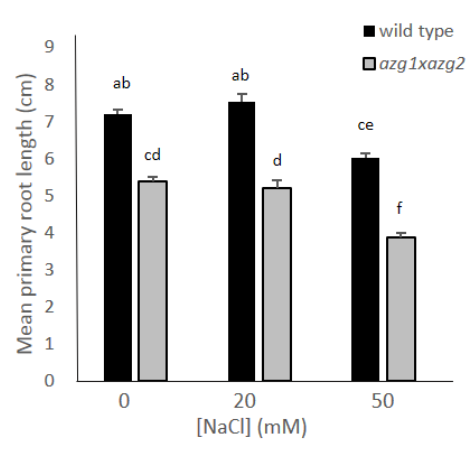

$50 \mathrm{mM}$ Mannitol
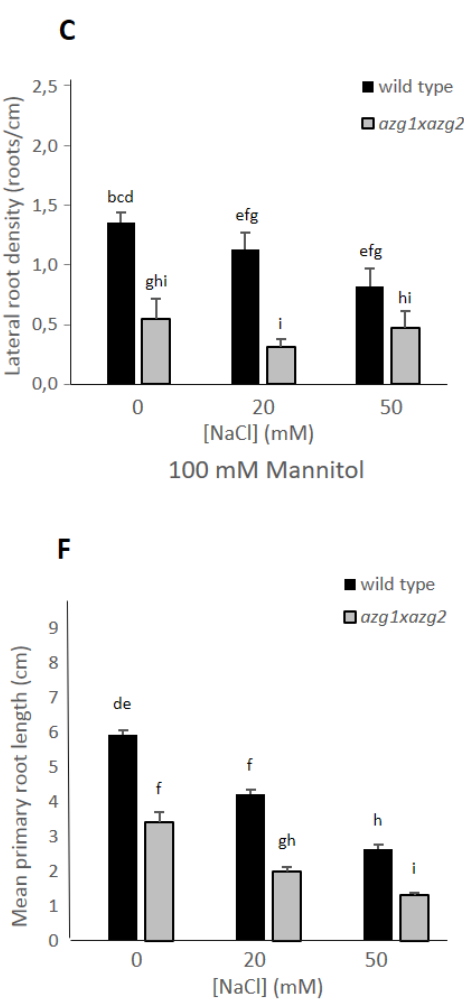

100 mM Mannitol 
Figure 7 AZG1 couples the response to drought and salinity in Arabidopsis roots. Seven-day old Arabidopsis plants were transferred to solid $1 / 2 \mathrm{MS}$ containing combinations of $0 \mathrm{mM}, 20 \mathrm{mM}$ or $50 \mathrm{mM} \mathrm{NaCl}$ and $(\mathrm{A}, \mathrm{D}) 0 \mathrm{mM}$ mannitol, (B, E) $50 \mathrm{mM}$ mannitol, (C, F) $100 \mathrm{mM}$ mannitol and grown for a further ten days. Letters indicate significantly different densities $(p<0.01)$ after a Tukey test. $22<n<58$.

In order to test whether $A Z G 1$ gene expression was altered upon exposure to $\mathrm{NaCl}$ in the region of the developing LR AZG1pro-dependent GUS transcription was observed. Transcription was not observed in the area which surrounded the emerging $L R$ primordium (Figure $8 \mathrm{~A}$ and $\mathrm{B}$ ), but became localised to vascular cells at the base of the elongating $\mathrm{LR}$ (Figure $8 \mathrm{C}$ ).

ARR5-dependent cytokinin signalling in vascular cells below the developing LR was dependent on the presence of $A Z G 1$ expression (Figure $8 D$ and $\mathrm{G}$ ). The application of $85 \mathrm{mM} \mathrm{NaCl}$ had a conspicuous effect on the distribution of ARR5pro:GUS-dependent staining in the emerging $\mathrm{LR}$, with staining in azg1-1 in the presence of $85 \mathrm{mM} \mathrm{NaCl}$ being localised to the emerging $\mathrm{LR}$ primordium (but absent from the stage II primordium) and being absent from subtending vascular cells on the proximal side of the root with respect to the emerging LR (Figure 8, E and F). This contrasted markedly with the staining pattern in the WT background, which displayed staining throughout the subtending vasculature and no staining in the emerging LR (but staining in the stage II primordium) (Figure $8, \mathrm{H}$ and I).

\section{pAZG1::GUS}
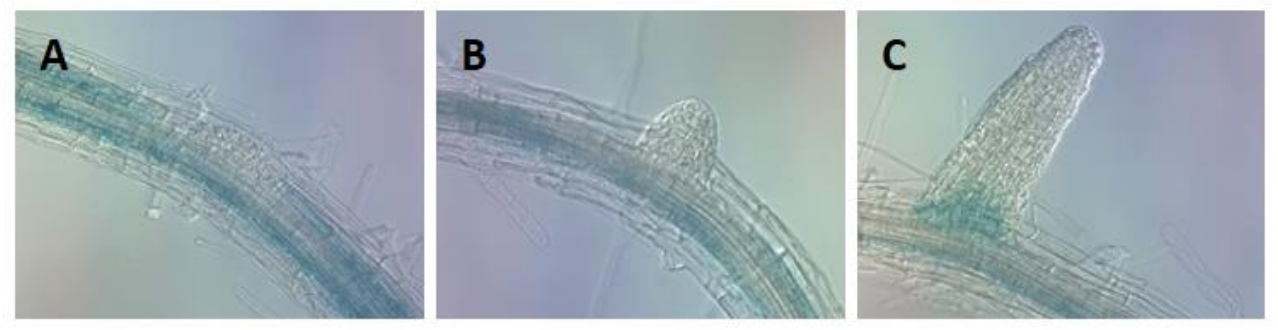

PARR5::GUS

$85 \mathrm{mM} \mathrm{NaCl}$

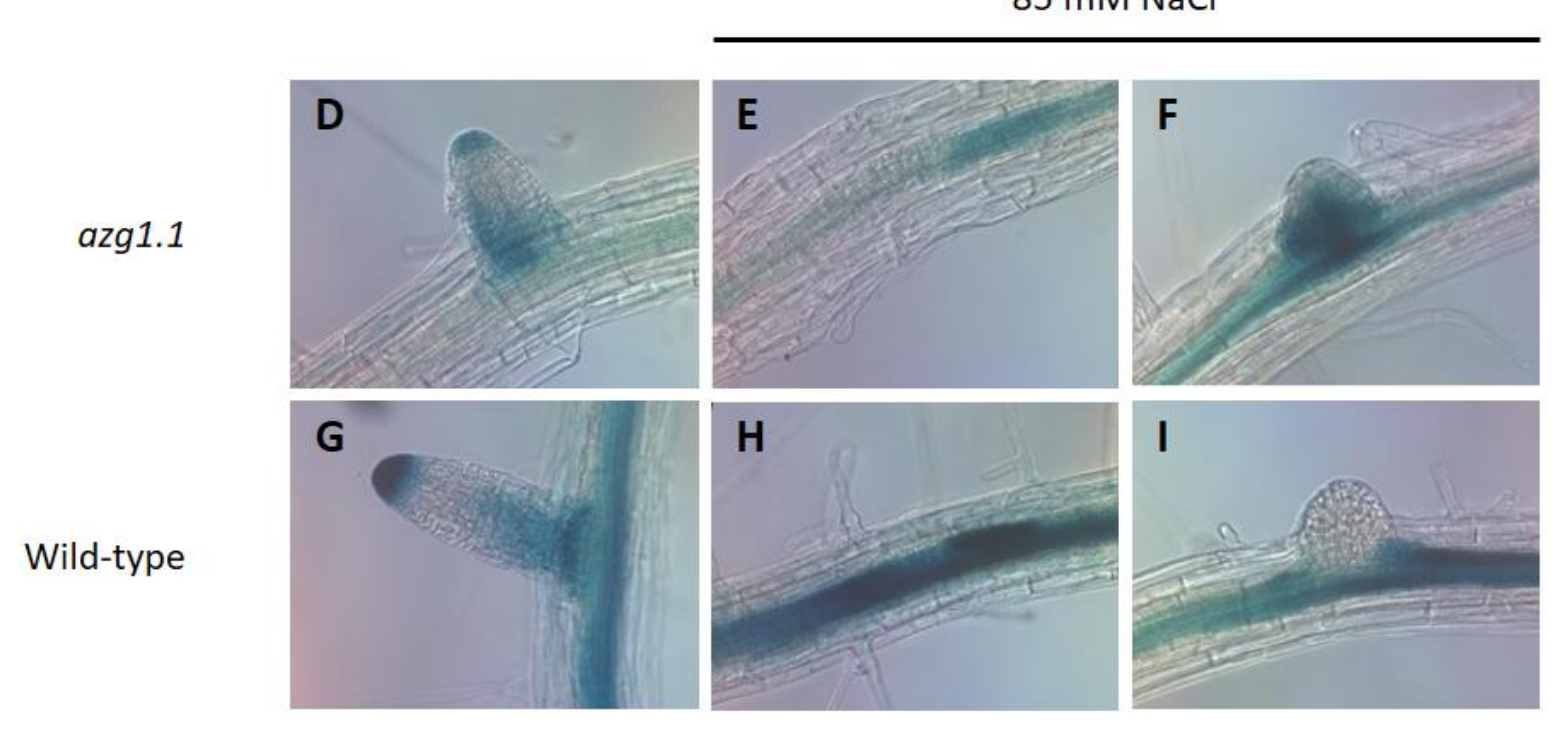


Figure 8 AZG1 influences lateral signaling in response to environmental sodium chloride. (A-C) AZG1pro:GUS staining in the emerging arabidopsis lateral root. ARR5:GUS staining in young lateral roots and their primordia in response to $85 \mathrm{mM} \mathrm{NaCl}(a q)$. (D-F) WT; (G-I) azg1-1; no treatment (D and G); (E, F, H and I) after growth on 85 $\mathrm{mM} \mathrm{NaCl}$.

\section{Discussion}

\section{Cytokinin transport}

Two principal long distance cytokinin (CK) transport streams have been characterized in flowering plants: those of trans-zeatin ( $t Z$ ) from the roots to the shoot via the xylem, and of $\mathrm{N}^{6}\left(\Delta^{2}\right.$-isopentyl)adenine (iP) and cis-zeatin ( $c Z$ ) from the shoots to the roots via the phloem. This transport is primed by members of three families of transporter protein: the purine permeases (PUPs), the equilibrative nucleotide transporters (ENTs), and the ATP-binding cassette ( $A B C$ ) transporters (Liu et al., 2019). The fact that these streams are both spatially and functionally distinct implies a degree of specificity among transporters for different cytokinin substrates, although quantitative data on transport rates and flux capacity of each transporter is currently sparse.

Despite CKs being synthesized in leaves (Kuroha et al., 2009), a series of careful grafting experiments has shown that the majority of $t Z$ which is present in the shoot is synthesized in roots and transported via the xylem (Matsumoto-Kitano et al., 2008). This work has been corroborated by the quantification of $\mathrm{CK}$ in vascular exudates which revealed that iP is the major CK in phloem streams, whereas $90 \%$ of an Arabidopsis plant's $t Z$ is present in the in the xylem, where $t Z$-riboside ( $t Z R$ ) accounted for $80 \%$ of all CK species measured (Hirose et al., 2008; Kudo et al., 2010; Ko et al., 2014). There is currently no strong evidence available that ENTs are involved in cellular $t Z$ uptake (Liu et al., 2019); moreover, those PUPs which have been classified as CK transporters (PUPs1 and 2), are likely to be responsible for the vascular loading of CK in leaves (Bürkle et al., 2003). Although ABCG14 is required for CK-dependent processes in the shoot, its localization supports the hypothesis that it is necessary for the loading of $t Z$ into xylem vessels in the elongation zone of the RAM (Zhang et al., 2014). Plants of $a b c g 14$, which accumulate $t Z$ in roots and dissipate $t Z$ in shoots, show CK-deficient shoot phenotypes such as thin stems containing a reduced number of vascular bundles, small rosettes and small flowers. In contrast to this, here we found that azg1 loss of function plants do not show such differences. These physiological observations, along with reduced $t z$ accumulation rates and resistance of root growth to exogenously applied $t Z$ in $a z g 1$ lead us to conclude that AZG1 is responsible for the cellular import of $t Z$ in the RAM, whereas ABCG14 is responsible for its cellular efflux. The expression domains of AZG1 and ABCG14 also imply their involvement in different processes: while AZG1 is localized to procambium cells in the division zone of the RAM (Figure 2D), ABCG14 is localized further from the root tip in cells of the elongation zone (Zhang et al., 2014). The expression pattern of AZG1 within the RAM largely resembles that of the CK signaling reporter TCSnpro:GFP (Figure S7; Zürchner et al., 2013). $t Z$ is supplied to the shoots from the roots (Beck and Wagner, 1994; Beveridge et al., 2000). Our data do not support the involvement of AZG1 in the long-distance shootward transport of this 
$t Z$; but rather a role for AZG1 in the retention of $t Z$ in via its cellular reuptake in the RAM (Figure 9A).

A

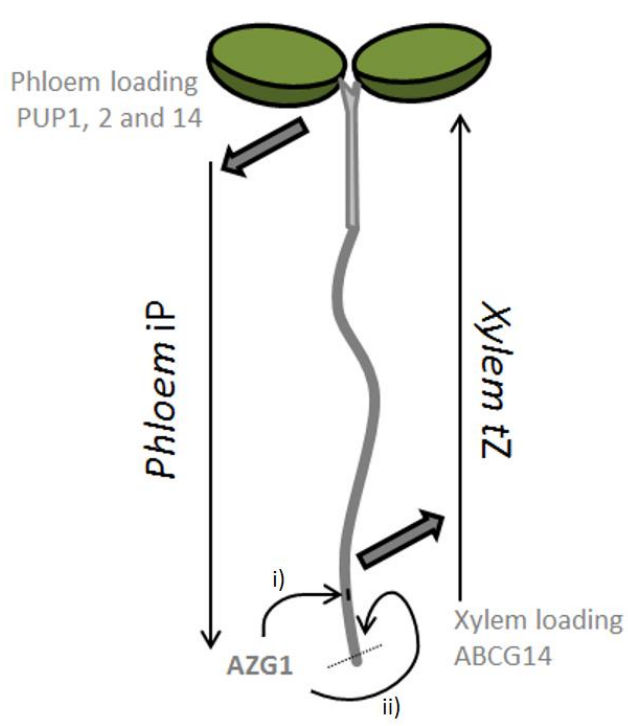

B

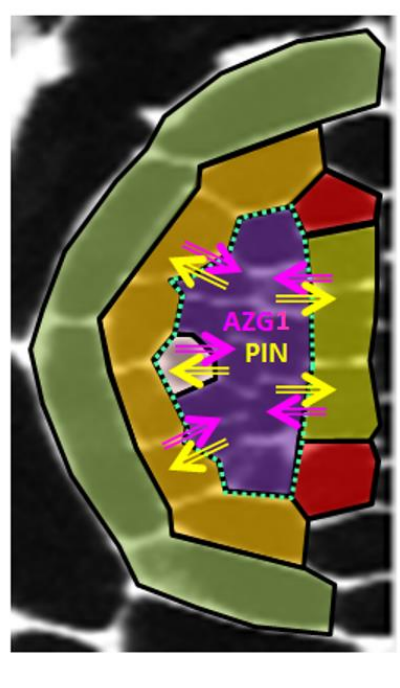

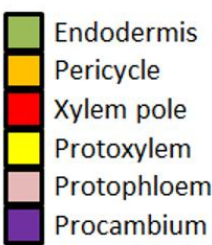

Hormone transport in procambium cells Cytokinin in through AZG1 Auxin out through PIN Sharpened boundary auxin/cytokinin

Figure 9 The context of AZG1-dependent cytokinin transport. A) Cytokinins are actively loaded into both phloem and xylem streams for bulk long-distance transport. The cellular localization of AZG1 suggests it is not involved in these processes, but rather in maintaining cytokinin signalling maxima in i) developing lateral roots and ii) the root apical meristem. B) AZG1 is localized to procambium cells where it acts simultaneously to stabilize cellular auxin efflux and cytokinin influx. This could affect sharpened boundary between auxin maxima in developing xylem cells, and cytokinin maxima in developing phloem cells.

\section{Cytokinin and patterning of the RAM}

This hypothesis may, however, easily be challenged as our careful cell-by-cell analysis showed that azg1 plants show no distinctive phenotype within the RAM. CK affects many cellular processes in the root including cell division, LR development, the response to abiotic stresses, and nodule development (Kieber and Schaller, 2018; Sasaki et al., 2014). It also shortens the length of the meristem itself in a process which is mediated by the transcriptional regulation of SHY2, a repressor of auxin-dependent transcription (dello loio et al., 2008). Surprisingly, and in contrast to the case seen in abcg14, the RAM of azg1 displayed a more constrained domain of CK signaling (as visualized by pARR5:GUS and TCSnpro:GFP expression), which one might have expected to confer an increased meristem size. That it did not, could be interpreted in terms of the functional significance of the AZG1-PIN1 interaction. AZG1 stabilizes PIN1 by reducing its rate of proteasome-dependent degradation. This observation would be consistent with a decrease in cellular auxin efflux in azg1 plants; a hypothesis consistent with our observations would therefore involve the PIN1-AZG1 interaction buffering cellular auxin:CK ratios via the coupling of auxin efflux regulation and CK influx within the RAM. The presence of additional CK transporter(s) at the plasma membrane during embryogenesis goes some way to rationalize the correlation which was observed between the localization of PUP14 in heart-stage embryos and areas of low CK signaling with the increasingly uncontroversial hypothesis that CK perception is localized at the ER (Zürchner et al., 2016; Romanov et al., 2018). 


\section{Posttranslational control of PIN1 by cytokinin}

The bilateral symmetry of vascular cells within the RAM is established and maintained by an intricate pattern of cross-talk between auxin and CK-mediated signaling systems (VaughanHirsch et al., 2018). At its core is the spatial separation of auxin and CK signaling cascades; auxin-mediated signals are localized to protoxylem cells, and CK signals to procambial and protophloem cells. This separation is maintained by transcriptionally mediated, but spatially defined, signaling mechanisms such as the induction of AHP6, a repressor of CK signaling, in protoxylem cells (Mähönen et al., 2006; Bishopp et al., 2011a). As well as its activity being thus suppressed in protoxylem cells, CK biosynthesis is up-regulated there by the production of LONELY GUY4 (LOG4), which is stimulated by the auxin-dependent transcription of TARGET OF MONOPTEROS5 (TMO5) and its dimerization with LONESOME HIGHWAY (LHW). In this model, CK then diffuses from protoxylem into procambial cells, where it is free to stimulate transcription.

AZG1 is localized to the plasma membrane of procambial, but not protoxylem, cells. It may not therefore be simple diffusion which mediates the crucial step of CK transfer between cell types, but an active uptake which is specifically confined to procambial cells. The binding and stabilization of PINs by AZG1 may also play a role in a second aspect of the proposed model. PIN7 relocalises in procambial cells in order to focus auxin into protoxylem cells (Bishopp et al, 2011b). The post-translational stabilization of PINs and AZG1 in procambial cell into lateral domains of mutual auxin efflux and CK influx would certainly be consistent with the proposed model (Figure 9B).

That CK influences the post-translational regulation of PIN proteins is already established. In stage III LR primordia, CK stimulates the removal of PIN1 from anticlinal membranes (Marharvý et al., 2014). This phenomenon is not cell-type specific, but is highly dependent on the sub-cellular localization of PIN proteins. Going forward it will be a priority to test whether the AZG1 dependent post-translational stabilization of PIN1 directly promotes LR emergence, and whether either subcellular AZG1 localization or AZG1-mediated cytokinin influx can mediate the post-translational response of PIN1 to cytokinin.

Despite displaying a restricted procambial cell CK signaling domain, and unlike other CKrelated mutants with a similar restriction in their CK signaling domain (e.g. $\log 3 / \log 4 / \log 7$, Ihw; Ohashi-Ito et al., 2014), azg1 seedlings show no RAM phenotype. As AZG1 potentially regulates auxin and $\mathrm{CK}$ transport and signaling processes simultaneously, it is conceivable that auxin: CK ratios may be only minimally affected in crucial cell types in azg1 when compared to WT roots. This simultaneous regulation may contribute to the robustness of root development. The localization of AZG1 in procambium cells of the RAM, together with a lack of any clear aerial phenotype, is probably more consistent with a role in the stabilization of tissue patterning mechanisms than in long distance CK transport. However, the possibility that AZG1 is involved in phloem unloading of iP remains open. Finally, a hypothesis involving the redundant effect of diverse CK transporters, allowing a lower but sufficient rate of CK influx, cannot yet be discarded. 


\section{Salt, cytokinin and root system architecture}

Cytokinin signaling has previously been broadly linked to plant responsiveness to the environment (Cortleven et al., 2019), as external conditions modulate CK homeostasis, for instance by altering its biosynthesis (Takei et al., 2004, Kuppu et al., 2013). The role of CK transport, and hence its physiological impact, may therefore influenced by environmental cues through the regulation of endogenous CK availability. This influence became evident after two independent investigations into the ABCG14 CK transporter. In these approaches, contrasting root elongation phenotypes were observed in identical abcg14 loss-of-function genotypes (Ko et al., 20014; Zhang et al., 2014). These differences could be ascribed to the different growth conditions used (e.g. in media composition and light/dark regime), indicating a strong buffering capacity of CK transporters with respect to changes in environmental conditions. Such a capacity may also be inferred for AZG1. When grown under high nitrate but short photoperiod (low C:N balance), azg1 plants developed longer and more complex root systems when compared to the wt (Fig $5 \mathrm{a}$ and b). This phenotype contrasted with that which was observed when plants were grown in the presence of $0.5 \mathrm{MS}$ media containing sucrose under a long-day photoperiod (high C:N balance; Fig 7A). Under a low C:N conditions, the systemic inhibition of root branching is triggered, increasing the amount of endogenous $\mathrm{CK}$ (Zhang et al., 1999; Takei et al., 2004). Under these conditions, lines which display a disturbed response to CK, such as azg1, would respond aberrantly to this systemic regulation. This effect has been also described for azg2, also recently characterized as being deficient in CK transport; this genotype showed a differential phenotype under a low C:N regime after the application of exogenous CK (Tessi et al., 2020).

Publicly available databases of transcriptional data (e.g. www.bar.utoronto.ca) indicate that AZG1 transcription is up-regulated after one hour of exposure to a $150 \mathrm{mM} \mathrm{NaCl}$ solution. These data were borne out by the experiments presented in this report, which recorded changes in the distribution of CK signaling maxima between azg1 and WT plants, but only after exposure to $\mathrm{NaCl}$. In Arabidopsis, $\mathrm{CK}$ plays an important role in the regulation of sodium ion concentration in root cells (Tran et al., 2007). However, the relationship between CK and soil salinity is multi-faceted and complex. For example, ARR1 and ARR12, two type-B CK response regulators, increase the accumulation of sodium ions in root xylem cells by repressing transcription of the gene encoding the sodium ion transporter AHK1.1 (Mason et al., 2010). Arabidopsis accessions showing relatively high HKT expression also bore fewer LRs (Julkowska et al., 2017). The absence of a functional AZG1 gene shifted CK signalling maxima into emerged LR primordia of salt-treated plants, but away from unemerged primordia. In combination with a loss-of-function azg2 allele, this conferred a LR system which, though slightly less dense than was observed in WT plants, was largely resistant to external $\mathrm{NaCl}$ solutions of up to $50 \mathrm{mM}$ (Figure. 7A). This insensitivity seemed decoupled from drought, as in the absence of $\mathrm{NaCl}, \mathrm{WT}$ and azg1-1 $x$ azg2-1 roots responded in the same way when exposed to mannitol concentrations of up to $100 \mathrm{mM}$ (Figure 7A-C). The hypothesis that AZG1 is also involved in CK-based root-shoot communication in response to increased soil sodicity is currently doubtful, as its localization makes it unlikely to be involved in the loading of $t Z$ into the xylem. 
Several morphological mechanisms are based on the well-defined and complementary distribution of auxin and CK signalling domains; however, it is still not known how CKs accumulate in specific cells (Bishopp et al., 2011a; Bishopp et al., 2011b; Bielach et al., 2012; De Rybel et al. 2014; Ohashi-Ito et al., 2014; Chang et al., 2015). Our observations involving salt treatment are consistent with AZG1 playing a role in the establishment and maintenance of sharp auxin-cytokinin concentration boundaries within the developing root through its interaction with PIN1 (Figure 9B).

\section{Acknowledgements}

The authors would like to thank K. Kratzat, Z. Kazimierzak and J. Dürr for valuable and expert technical assistance. This work was supported by Bundesministerium für Bildung und Forschung (BMBF SYSBRA, SYSTEC, Microsystems), the Excellence Initiative of the German Federal and State Governments (EXC 294), the German Research Foundation (DFG SFB746 and INST 39/839,840,841), the National Fund of Science and Technology (FONCyT, Argentina, PICT2009-0114) and a Grant of the Secretary of Science and Technology of the National University of Córdoba (SECYT-UNC). The work of VGM was supported by the Heisenberg Program of the German Research Foundation (DFG) through grants MA2379/9-1 and MA2379/9-2. The authors declare that no competing interests exist.

\section{Author contributions}

V.M., M.D. K.P. and W.T. conceived the study, V.M., M.D., V.M., T.T. and W.T. wrote the manuscript. T.T., M.S., V.M., E.M., T.P., B.S., K.K., JD., N.F., M.N., Z.K., A.W., M.D. and W.T. Planned and performed experiments and analysed data, T.T., M.S., V.M, M.D. and W.T were responsible for the resources. O.N. and M.S planned and performed metabolomic analysis, JT: planned and performed proteomic analysis, V.M, K.P., M.D. and W.T supervised the study. V.M., K.P. and M.D. acquired the funding.

\section{Supplementary Figure Legends}

Supplementary Figure 1 Candidate PIN1 interactors which did not show direct physical interaction with PIN1 in co-immunoprecipitation assay. A) ADL1:YFP. Immunoprecipitate of ADL1:YFP was analyzed for the presence of PIN1 by western blotting (WB) with anti-PIN1 antibodies. Asterisk indicates full-length PIN1 protein. B) SMT2:HA. Immunoprecipitate of PIN1:YFP was analyzed for the presence of SMT2:HA by WB with anti-HA antibodies. Asterisk indicates SMT2:HA. Protein extract from untransformed tobacco leaves served as a negative control for immunodetection of HA-tagged fusion protein (WB control).

Supplementary Figure 2 Relative endogenous cytokinin (CK) content in rosette leaves of WT and azg1-1 plants grown on solid MS either (A) without or (B) containing $200 \mathrm{nM}$ tZ. Bars show standard deviation. $\mathrm{N}=4$. $\mathrm{tZ}$, trans-Zeatin; tZR, trans-Zeatin riboside; tZ9G, trans-Zeatin-9Glucoside; tZOG, O-Glucosyl-trans-Zeatin; tZROG, O-Glucsyl-trans-Zeatinriboside; iPR, Isopentenyl-adeninriboside; iPR-5'MP, Isopentenyl-adenin riboside-5'Monophosphate; iP9G, Isopentenyl-adenine-9-Glucoside. For every cytokinin and derivative, relative values were 
calculated in comparison to tissue from plants not grown on tZ. Values for WT plants were normalized to a value of 1 . Actual values are given in brackets.

Supplementary Figure 3 A) RT-PCR analysis of AZG1 expression in different plant organs. (B) Bending angle after a $90^{\circ}$ rotation of growing plates.

Supplementary Figure 4 Immunolocalization of PIN1, showing its localization in roots of $(A)$ WT, (B) azg1-1, and (C) azg1-1 x azg2-1 four-day old seedlings.

Supplementary Figure 5 Leaf regeneration is inhibited in azg1 calli A) Graph shows Arabidopsis thaliana root explants grown on solid callus-inducing medium and transferred to solid $1 / 2$ MS medium containing the indicated concentration of kinetin and incubated for 18 days. B) An example image of regenerating calli developing leaves in AM supplemented with $0.46 \mu \mathrm{M}$ kinetin.

Supplementary Figure 6 AZG1-, auxin- and CK-dependent expression in response to root apical meristem ablation. A) AZG1pro:GUS B) TCSpro:GFP in regenerating root apices. Scale bars $=200 \mu \mathrm{m}$.

Supplementary Figure $7 \mathrm{CK}$ signalling in the azg1 RAM. (A) Col-0 and azg1 genetic backgrounds were transformed with the TCSnpro:GFP CK reporter. Representative RAMs are shown in (A). White arrows indicate where a change in signalling pattern is observed in meristematic stele cells of azg1-1. (B) GFP signal intensity average across the zone highlighted in a dashed yellow rectangle in (A) of WT and azg1-1 backgrounds. Bar $=100 \mu \mathrm{m}$.

Supplementary Figure 8 iRoCS analysis of root dimensions in the Arabidopsis root apical meristem. (A) Average meristematic cell length, (B) cell-file-dependent meristem length (distance from QC), and (C) cell length as a function of distance from the QC. WT (clear); azg11 (shaded). Bars indicate standard deviation. 


\section{References}

Aloni R, Aloni $\mathrm{E}$, Langhans $\mathrm{M}$ and Ullrich $\mathrm{Cl}$ (2006) Role of cytokinin and auxin in shaping root architecture: regulating vascular differentiation, lateral root initiation, root apical dominance and root gravitropism. Annals of Botany 97: 883-93

Argueso CT, Ferreira FJ and Kieber JJ (2009) Environmental perception avenues: the interaction of cytokinin and environmental response pathways. Plant Cell Environ 32:114760

Beck E and Wagner BM (1994) Quantification of the daily cytokinin transport from the root to the shoot of Urtica dioica. Botanica acta 107: 342-348

Bielach A, Podlesáková K, Marhavy P, Duclercq J, Cuesta C, Müller B, Grunewald W, Tarkowski $P$ and Benková E (2012) Spatiotemporal regulation of lateral root organogenesis in Arabidopsis by cytokinin. Plant Cell 24:3967-81

Benková E, Michniewicz M, Sauer M, Teichmann T, Seifertová D, Jürgens G and Friml J (2003) Local, efflux-dependent auxin gradients as a common module for plant organ formation. Cell 115:591-602

Beveridge CA (2000) Long-distance signalling and a mutational analysis of branching in pea. Plant growth regulation 32: 193-203

Bishopp A, Help H, El-Showk S, Weijers D, Scheres B, Friml J, Benková E, Mähönen AP and Helariutta Y. (2011a) A mutually inhibitory interaction between auxin and cytokinin specifies vascular pattern in roots. Current Biology 21: 917-26

Bishopp A, Lehesranta S, Vaten A, Help H, El-Showk S, Scheres B, Helariutta K, Mahonen AP, Sakakibara $\mathrm{H}$ and Helariutta $Y$ (2011b) Phloem-transported cytokinin regulates polar auxin transport and maintains vascular pattern in the root meristem. Curr Biology 21: 927-932

Blagoev B, Ong SE, Kratchmarova I and Mann M (2004) Temporal analysis of phosphotyrosine-dependent signalling networks by quantitative proteomics. Nature Biotechnol. 22: 1139-1145

Blilou I, Xu J, Wildwater M, Willemsen V, Paponov I, Friml J, Heidstra R, Aida M, Palme K and Scheres B. (2005) The PIN auxin efflux facilitator network controls growth and patterning in Arabidopsis roots. Nature 433:39-44

Bürkle L, Cedzich A, Döpke C, Stransky H, Okumoto S, Gillissen B, Kühn C and Frommer WB. (2003) Transport of cytokinins mediated by purine transporters of the PUP family expressed in phloem, hydathodes, and pollen of Arabidopsis. Plant Journal 34: 13-26

Caesar K, Thamm AMK, Witthoeft J, Elgass K, Huppenberger P, Grefen C, Horak J and Harter $K$ (2011) Evidence for the localization of the Arabidopsis cytokinin receptors AHK3 and AHK4 in the endoplasmic reticulum. Journal of Experimental Botany 62: 5571-5580 
Carland FM, Fujioka S,Takatsuto S, Yoshida S and Nelson T (2002) The Identification of CVP1 Reveals a Role for Sterols in Vascular Patterning. Plant Cell 14: 2045-2058

Cecchetto G, Amillis S, Diallinas G, Scazzocchio C, Drevet C (2004) The AzgA purine transporter of Aspergillus nidulans. Characterization of a protein belonging to a new phylogenetic cluster. J Biol Chem 279:3132-41

Chang L, Ramireddy E and Schmülling T (2015) Cytokinin as a positional cue regulating lateral root spacing in Arabidopsis. J Exp Bot 66:4759-68

Cortleven A, Leuendorf JE, Frank M, Pezzetta D, Bolt S and Schmülling T (2019) Cytokinin action in response to abiotic and biotic stresses in plants. Plant, Cell \& Environment 42:9981018

dello loio R, Nakamura K, Moubayidin L, Perilli S, Taniguchi M, Morita MT, Aoyama T, Costantino $P$ and Sabatini S (2008) A genetic framework for the control of cell division and differentiation in the root meristem. Science 322: 1380-1384

De Rybel B, Adibi M, Breda AS, Wendrich JR, Smit ME, Novák O, Yamaguchi N, Yoshida S, Van Isterdael G, Palovaara J, Nijsse B, Boekschoten MV, Hooiveld G, Beeckman T, Wagner D, Ljung K, Fleck C and Weijers D (2014) Plant development. Integration of growth and patterning during vascular tissue formation in Arabidopsis. Science 345:1255215

Desimone M, Catoni E, Ludewig U, Hilpert M, Schneider A, Kunze R, Tegeder M, Frommer WB and Schumacher K. (2002) A novel superfamily of transporters for allantoin and other oxo derivatives of nitrogen heterocyclic compounds in Arabidopsis. Plant Cell 14:847-56

Ditengou FA, Teale WD, Kochersperger P, Flittner KA, Kneuper I, Van Der Graaff E, Nziengui $\mathrm{H}$, Pinosa F, Li X, Nitschke R, Laux T and Palme K (2008) Mechanical induction of lateral root initiation in Arabidopsis thaliana. Proceedings of the National Academy of Sciences of the United States of America 105: 18818-18823

Dubrovsky JG, Sauer M, Napsucialy-Mendivil S, Ivanchenko MG, Friml J, Shishkova S, Celenza $J$ and Benkova E (2008) Auxin acts as a local morphogenetic trigger to specify lateral root founder cells. Proceedings of the National Academy of Sciences of the United States of America 105: 8790-8794

Fahnenstich H, Saigo M, Niessen M, Zanor MI, Andreo CS, Fernie AR, Drincovich MF, Flügge UI, Maurino VG (2007) Alteration of organic acid metabolism in Arabidopsis overexpressing the maize C4 NADP-malic enzyme causes accelerated senescence during extended darkness. Plant Physiology 145:640-52

Faiss M, Zalubìlová J, Strnad M and Schmülling T (1997) Conditional transgenic expression of the ipt gene indicates a function for cytokinins in paracrine signaling in whole tobacco plants. Plant J 12: 401-15. 
Friml J, Wiśniewska J, Benková E, Mendgen K and Palme K (2002) Lateral relocation of auxin efflux regulator PIN3 mediates tropism in Arabidopsis. Nature 415: 806-809

Grefen C, Donald N, Hashimoto K, Kudla J, Schumacher K, Blatt MR. (2010) A ubiquitin-10 promoter-based vector set for fluorescent protein tagging facilitates temporal stability and native protein distribution in transient and stable expression studies. Plant J 64: 355-365

Grieneisen VA, Xu J, Maree AFM, Hogeweg P and Scheres B (2007) Auxin transport is sufficient to generate a maximum and gradient guiding root growth. Nature 449: 1008-1013

Hirose N, Takei K, Kuroha T, Kamada-Nobusada T, Hayashi H and Sakakibara H (2008) Regulation of cytokinin biosynthesis, compartmentalization and translocation. Journal of Experimental Botany 59:75-83

Julkowska MM, Koevoets IT, Mol S, Hoefsloot H, Feron R, Tester MA, Keurentjes JJB, Korte A, Haring MA, de Boer GJ and Testerink C (2017) Genetic Components of Root Architecture Remodeling in Response to Salt Stress. Plant Cell 29: 3198-321

Julkowska MM, Testerink C. (2017) Tuning plant signaling and growth to survive salt. Trends in Plant Science 9: 586-94

Kieber and Schaller (2018) Cytokinin signaling in plant development. Development 145: $\operatorname{dev} 149344$

Kjellbom P and Larsson C (1984) Preparation and polypeptide composition of cMorophyllfreeplasma membranes from leaves of light-grown spinach and barley. Physiologia Plantarum 62: 501-509

Ko D, Kang J, Kiba T, Park J, Kojima M, Do J, Kim KY, Kwon M, Endler A, Song WY, Martinoia E, Sakakibara $\mathrm{H}$ and Lee $\mathrm{Y}$ (2014) Arabidopsis ABCG14 is essential for the root-to-shoot translocation of cytokinin. Proceedings of the National Academy of Sciences of the United States of America 111: 7150-5

Kudo T, Kiba T and Sakakibara H (2010) Metabolism and long-distance translocation of cytokinins. Journal of Integrated Plant Biology 52: 53-60

Kuppu S, Mishra N, Hu R, Sun L, Zhu X, Shen G, Blumwald E, Payton P and Zhang H (2013) Water-deficit inducible expression of a cytokinin biosynthetic gene IPT improves drought tolerance in cotton. PLoS One 8:e64190

Kuroha T, Tokunaga H, Kojima M, Ueda N, Ishida T, Nagawa S, Fukuda H, Sugimoto K and Sakakibara $H$ (2009) Functional analyses of LONELY GUY cytokinin-activating enzymes reveal the importance of the direct activation pathway in Arabidopsis. Plant Cell 21:3152-69

Laplaze L, Benkova E, Casimiro I, Maes L, Vanneste S, Swarup R, Weijers D, Calvo V, Parizot B, Herrera-Rodriguez MB, Offringa R, Graham N, Doumas P, Friml J, Bogusz D, Beeckman T and 
Bennett M (2007) Cytokinins act directly on lateral root founder cells to inhibit root initiation. Plant Cell 19: 3889-3900

Liu CJ, Zhao Y and Zhang K (2019) Cytokinin Transporters: Multisite Players in Cytokinin Homeostasis and Signal Distribution. Frontiers in Plant Science 10: 693

Mähönen AP, Bishopp A, Higuchi M, Nieminen KM, Kinoshita K, Törmäkangas K, Ikeda Y, Oka A, Kakimoto T and Helariutta Y (2006) Cytokinin signaling and its inhibitor AHP6 regulate cell fate during vascular development. Science 311: 94-8

Mansfield TA, Schultes NP and Mourad GS (2009) AZG1 and AtAzg2 comprise a novel family of purine transporters in Arabidopsis. Febs Letters 583: 481-486

Marhavý P, Bielach A, Abas L, Abuzeineh A, Duclercq J, Tanaka H, Parezova M, Petrasek J, Friml J, Kleine-Vehn J and Benkova E (2011) Cytokinin Modulates Endocytic Trafficking of PIN1 Auxin Efflux Carrier to Control Plant Organogenesis. Developmental Cell 21: 796-804

Marhavý P, Duclercq J, Weller B, Feraru E, Bielach A, Offringa R, Friml J, Schwechheimer C, Murphy A and Benkova E (2014) Cytokinin Controls Polarity of PIN1-Dependent Auxin Transport during Lateral Root Organogenesis. Current Biology 24: 1031-1037

Mason MG, Jha D, Salt DE, Tester M, Hill K, Kieber JJ and Schaller GE (2010) Type-B response regulators ARR1 and ARR12 regulate expression of AtHKT1;1 and accumulation of sodium in Arabidopsis shoots. Plant J 64: 753-63

Matsumoto-Kitano M, Kusumoto T, Tarkowski P, Kinoshita-Tsujimura K, Václavíková K, Miyawaki K and Kakimoto T (2008) Cytokinins are central regulators of cambial activity. Proceedings of the National Academy of Sciences of the United States of America 105: 2002731

Maurino VG, Grube E, Zielinski J, Schild A, Fischer K and Flügge UI (2006) Identification and expression analysis of twelve members of the nucleobase-ascorbate transporter (NAT) gene family in Arabidopsis thaliana. Plant Cell Physiology 47: 1381-93

Menges M and Murray JA (2002) Synchronous Arabidopsis suspension cultures for analysis of cell-cycle gene activity. Plant J 30: 203-12

Möhlmann T, Mezher Z, Schwerdtfeger G and Neuhaus HE (2001) CCharacterisation of a concentrative type of adenosine transporter from Arabidopsis thaliana (ENT1,At). FEBS Letters 509: 370-4

Mravec J, Petrášek J, Li N, Boeren S, Karlova R, Kitakura S, Pařezová M, Naramoto S, Nodzyński T, Dhonukshe P, Bednarek SY, Zažímalová E, de Vries S and Friml J (2011) Cell plate restricted association of DRP1A and PIN proteins is required for cell polarity establishment in Arabidopsis. Current Biology 21:1055-60

Muller B and Sheen J (2008) Cytokinin and auxin interaction in root stem-cell specification during early embryogenesis. Nature 453: 1094-1097 
Murashige T and Skoog F (1962) A revised medium for rapid growth and bio assays with tobacco tissue cultures. Physiolgia Plantarum 15: 473-497

Niopek-Witz S, Deppe J, Lemieux MJ and Möhlmann T (2014) Biochemical characterization and structure-function relationship of two plant NCS2 proteins, the nucleobase transporters NAT3 and NAT12 from Arabidopsis thaliana. Biochem Biophys Acta. 1838:3025-35

O'Brien JA and Benková E (2013) Cytokinin cross-talking during biotic and abiotic stress responses. Frontiers in plant science 4: 451.

Ohashi-Ito K, Saegusa M, Iwamoto K, Oda Y, Katayama H, Kojima M, Sakakibara H and Fukuda H. (2014) A bHLH complex activates vascular cell division via cytokinin action in root apical meristem Current Biology 24: 2053-8

Ottenschläger I, Wolff P, Wolverton C, Bhalerao RP, Sandberg G, Ishikawa H, Evans M and Palme K (2003) Gravity-regulated differential auxin transport from columella to lateral root cap cells. Proceedings of the National Academy of Sciences of the United States of America 100: 2987-2991

Perkins DN, Pappi, DJ, Creasy DM and Cottrell JS (1999) Probability-based protein identification by searching sequence databases using mass spectrometry data.

Electrophoresis 20: 3551-3567

Petrasek J, Mravec J, Bouchard R, Blakeslee JJ, Abas M, Seifertova D, Wisniewska J, Tadele Z, Kubes M, Covanova M, Dhonukshe P, Skupa P, Benkova E, Perry L, Krecek P, Lee OR, Fink GR, Geisler M, Murphy AS, Luschnig C, Zazimalova E and Friml J (2006) PIN proteins perform a rate-limiting function in cellular auxin efflux. Science 312: 914-918

Romanov GA, Lomin SN and Schmülling T (2018) Cytokinin signaling: from the ER or from the PM? That is the question! New Phytologist 218: 41-53

Rozema J and Flowers, T (2008) Crops for a Salinized World. Science 322 1478-1480

Sasaki T, Suzaki T, Soyano T, Kojima M, Sakakibara H and Kawaguchi M (2014) Shoot-derived cytokinins systemically regulate root nodulation. Nature Communications 19: 4983

Schmidt T, Pasternak T, Liu K, Blein T, Aubry-Hivet D, Dovzhenko A, Duerr J, Teale W, Ditengou FA, Burkhardt H, Ronneberger O and Palme K. (2014) The iRoCS Toolbox--3D analysis of the plant root apical meristem at cellular resolution. Plant J 77: 806-14

Shevchenko A, Wilm M, Vorm O and Mann M (1996) Mass spectrometric sequencing of proteins from silver-stained polyacrylamide gels. Anal Chem 68: 850-858

Swamy M, Siegers GM, Minguet S, Wollscheid B and Schamel WW. (2006) Blue native polyacrylamide gel electrophoresis (BN-PAGE) for the identification and analysis of multiprotein complexes. Sci STKE. 345:p14. 
Takei K, Ueda N, Aoki K, Kuromori T, Hirayama T, Shinozaki K, Yamaya T and Sakakibara H (2004) AtIPT3 is a key determinant of nitrate-dependent cytokinin biosynthesis in Arabidopsis. Plant Cell Physiology 45:1053-62

Tessi TM, Brumm S, Winklbauer E, Schumacher B, Lescano Cl, González CA, Wanke D, Maurino VG, Harter K and Desimone M (2020) Arabidopsis AZG2, an auxin induced putative cytokinin transporter, regulates lateral root emergence. New Phytologist In press

Tran LP, Urao T, Qin F, Maruyama K, Kakimoto T, Shinozaki K and Yamaguchi-Shinozaki K (2007) Functional analysis of AHK1/ATHK1 and cytokinin receptor histidine kinases in response to abscisic acid, drought, and salt stress in Arabidopsis. Proceedings of the National Academy of Sciences of the United States of America 104: 20623-20628

van den Berg C, Willemsen V, Hendriks G, Weisbeek B and Scheres B (1997) Short-range control of cell differentiation in the Arabidopsis Root meristem. Nature 390: 287-9

Vaughan-Hirsch J, Goodall B and Bishopp A (2018) North, East, South, West: mapping vascular tissues onto the Arabidopsis root. Current Opinion in Plant Biology 41: 16-22

Werner T, Nehnevajova E, Köllmer I, Novák O, Strnad M, Krämer U and Schmülling T (2010) Root-specific reduction of cytokinin causes enhanced root growth, drought tolerance, and leaf mineral enrichment in Arabidopsis and tobacco Plant Cell 22:3905-20

Xu J, Hofhuis H, Heidstra R, Sauer M, Friml J and Scheres B (2006) A molecular framework for plant regeneration. Science 311: 385-8

Xuan W, De Gernier H and Beeckman T (2020) The Dynamic Nature and Regulation of the Root Clock. Development 147: 1-11

Zhang $\mathrm{H}$, Jennings A, Barlow P and Forde B (1999) Dual pathways for regulation of root branching by nitrate. Proceedings of the National Academy of Sciences of the United States of America 96: 6529-6534

Zhang K, Novak O, Wei Z, Gou M, Zhang X, Yu Y, Yang H, Cai Y, Strnad M and Liu CJ. (2014) Arabidopsis ABCG14 protein controls the acropetal translocation of root-synthesized cytokinins. Nature Communications 5:3274

Zolla G, Heimer Y and Barak S (2010) Mild salinity stimulates a stress-induced morphogenic response in Arabidopsis thaliana roots. Journal of Experimental Botany 61: 211-224

Zürcher E, Tavor-Deslex D, Lituiev D, Enkerli K, Tarr PT and Müller B (2013) A robust and sensitive synthetic sensor to monitor the transcriptional output of the cytokinin signaling network in planta. Plant Physiology 161:1066-75

Zürcher E, Liu J, di Donato M, Geisler M and Müller B (2016) Plant development regulated by cytokinin sinks. Science 353: 1027-1030 
bioRxiv preprint doi: https://doi.org/10.1101/2020.10.22.350363; this version posted October 22, 2020. The copyright holder for this preprint (which was not certified by peer review) is the author/funder. All rights reserved. No reuse allowed without permission. 